Article

\title{
An Adaptive Model Predictive Load Frequency Control Method for Multi-Area Interconnected Power Systems with Photovoltaic Generations
}

\author{
Guo-Qiang Zeng ${ }^{1, *}$, Xiao-Qing Xie ${ }^{1}$ and Min-Rong Chen ${ }^{2}$ \\ 1 National-Local Joint Engineering Laboratory of Digitalize Electrical Design Technology, Wenzhou University, \\ Wenzhou 325035, China; xiaoqingxie@stu.wzu.edu.cn \\ 2 School of Computer, South China Normal University, Guangzhou 510631, China; mrongchen@126.com \\ * Correspondence: zenggq@wzu.edu.cn or zeng.guoqiang5@gmail.com; Tel.: +86-15967405738
}

Received: 15 October 2017; Accepted: 9 November 2017; Published: 11 November 2017

\begin{abstract}
As the penetration level of renewable distributed generations such as wind turbine generator and photovoltaic stations increases, the load frequency control issue of a multi-area interconnected power system becomes more challenging. This paper presents an adaptive model predictive load frequency control method for a multi-area interconnected power system with photovoltaic generation by considering some nonlinear features such as a dead band for governor and generation rate constraint for steam turbine. The dynamic characteristic of this system is formulated as a discrete-time state space model firstly. Then, the predictive dynamic model is obtained by introducing an expanded state vector, and rolling optimization of control signal is implemented based on a cost function by minimizing the weighted sum of square predicted errors and square future control values. The simulation results on a typical two-area power system consisting of photovoltaic and thermal generator have demonstrated the superiority of the proposed model predictive control method to these state-of-the-art control techniques such as firefly algorithm, genetic algorithm, and population extremal optimization-based proportional-integral control methods in cases of normal conditions, load disturbance and parameters uncertainty.
\end{abstract}

Keywords: load frequency control; multi-area interconnected power systems; photovoltaic generation; model predictive control; proportional-integral control

\section{Introduction}

Load-frequency control (LFC) issue in a multi-area interconnected power system is essentially to design an effective and efficient controller to match the total generations with the total load demand and the corresponding system losses. In other words, the main objective of LFC is to minimize the frequency deviations of each area and tie-line power flows between neighboring control areas subjecting to some pre-specified tolerances when load demands fluctuate or resonance attack [1,2]. Over the past four decades, a variety of great achievements have been made for the LFC issueof traditional power systems. For example, as the most popular control technique, proportional-integral-derivative (PID) controller and its various variations have been widely applied to the LFC issue [3-8]. Moreover, some researchers have paid more attention to the advanced control theories based LFC methods recently, such as robust control theories [9], model predictive control [10-14], sliding mode control [15,16], neural network control [17], internal model control [18], and differential games [19]. It should be noted that there are different evolutionary algorithms based PID or proportional-integral (PI) control methods for the LFC issue of multi-area power systems. For example, genetic algorithm 5,6, hybrid particle swarm optimization [20], differential evolution [21,22], imperial competitive algorithm [23], firefly algorithm [24], non-dominated sorting genetic algorithm-II (NSGA-II) [8], multi-objective optimization 
using weighted sum artificial bee colony algorithm [7], and a evolutionary many-objective optimization algorithm with clustering-based selection called EMyO/C [25] have been utilized to tune PID or PI controllers for the LFC issue.

As increased penetration level of renewable distributed generations such as wind turbine generator and photovoltaic stations, these renewable generations affects the LFC problem of multi-area power system tremendously. The effects of wind turbine generators on LFC issues of multi-area power systems have been discussed recently [26-31]. Unfortunately, only few research works contribute to the LFC problem of multi-area power system with photovoltaic (PV) generations. Abd-Elazim and Ali [32] proposed firefly algorithm (FA)-based PI controllers for LFC of a two-area power system composing of a photovoltaic (PV) system and a thermal generator, and its effectiveness is demonstrated by comparing the performance with genetic algorithm (GA)-based PI control method for this system under load disturbance and parameters uncertainty conditions. However, the nonlinear features such as the dead band (DB) for governor and generation rate constraint (GRC) for steam turbine have not been considered in the recently reported work [32]. By taking into account these nonlinear features, how to further improve the LFC performance of a multi-area power system with PV generation especially under dynamical loads fluctuations is still a challenging issue.

On the other hand, model predictive control (MPC) ranks second after PID as the most widely-applied control methods in industry [33,34]. Compared to PID controller, MPC has some significant advantages including fast response and stronger robustness against load disturbance and parameters uncertainty. Especially, one prominent characteristics of MPC is predicting the future behavior of the desired control variables based on a minimization cost function until a predefined horizon in time. With the rapid development of high-speed microprocessors, MPC has been applied increasingly to "fast-process" systems such as power converters and power systems in the past decade [10-14,35-41]. However, to the best of the authors' knowledge, MPC has never applied to the optimal LFC issue of multi-area power system with PV generations.

Motivated by the above analysis, we propose an adaptive model predictive load frequency control method for a multi-area interconnected power system with PV generation. The key idea behind the proposed method is formulating the dynamic load frequency control issue as a discrete-time state space model, obtaining the predictive dynamic model by introducing an expanded state vector, and rolling optimization of control output signal based on a cost function by minimizing the weighted sum of square predicted errors and square future control values. The simulation results on a typical two-area power system consisting of PV and thermal generator will demonstrate the superiority of the proposed MPC method to these existing evolutionary algorithms-based PI control methods such as FA-PI [32] GA-PI [32], and population extremal optimization-based PI denoted as PEO-PI [42,43] in cases of normal condition, load disturbance and parameters uncertainty.

The main contribution of this work is described as follows:

(1) To the best of the authors' knowledge, an extended MPC method with an extended state vector is proposed firstly for the optimal LFC issue of a multi-area interconnected power system with PV generation.

(2) Compared with two state-of-the-art control methods reported in [32], this proposed MPC method considers some nonlinear features such as DB and GRC in a thermal system.

(3) In cases of load disturbance and parameters uncertainty, the proposed MPC method can improve the control performance of a multi-area interconnected power system with PV generation compared with these state-of-the-art control methods [32,42].

The rest of this paper is organized as follows. Section 2 presents the dynamic model of a two-area power system consisting of PV and thermal generator. In Section 3, an adaptive MPC based LFC method is proposed for a multi-area power system with PV generation. The comparative studies on a typical test system in cases of normal condition, load disturbance and parameters uncertainty are provided in Section 4. Finally, we give the conclusions and open problems in Section 5. 


\section{System Model}

\subsection{Small-Signal Model}

Figure 1 shows the block diagram of a two-area interconnected power system composed of a PV system(area 1) and a thermal system (area 2) [32]. It should be noted that there are some important nonlinear features in a thermal system such as the dead band (DB) for governor and generation rate constraint (GRC) for steam turbine, but these nonlinear features has never been considered in the recently reported work [32]. In order to make up this defect, this paper introduces these nonlinearities including DB and GRC in a thermal system [44,45].

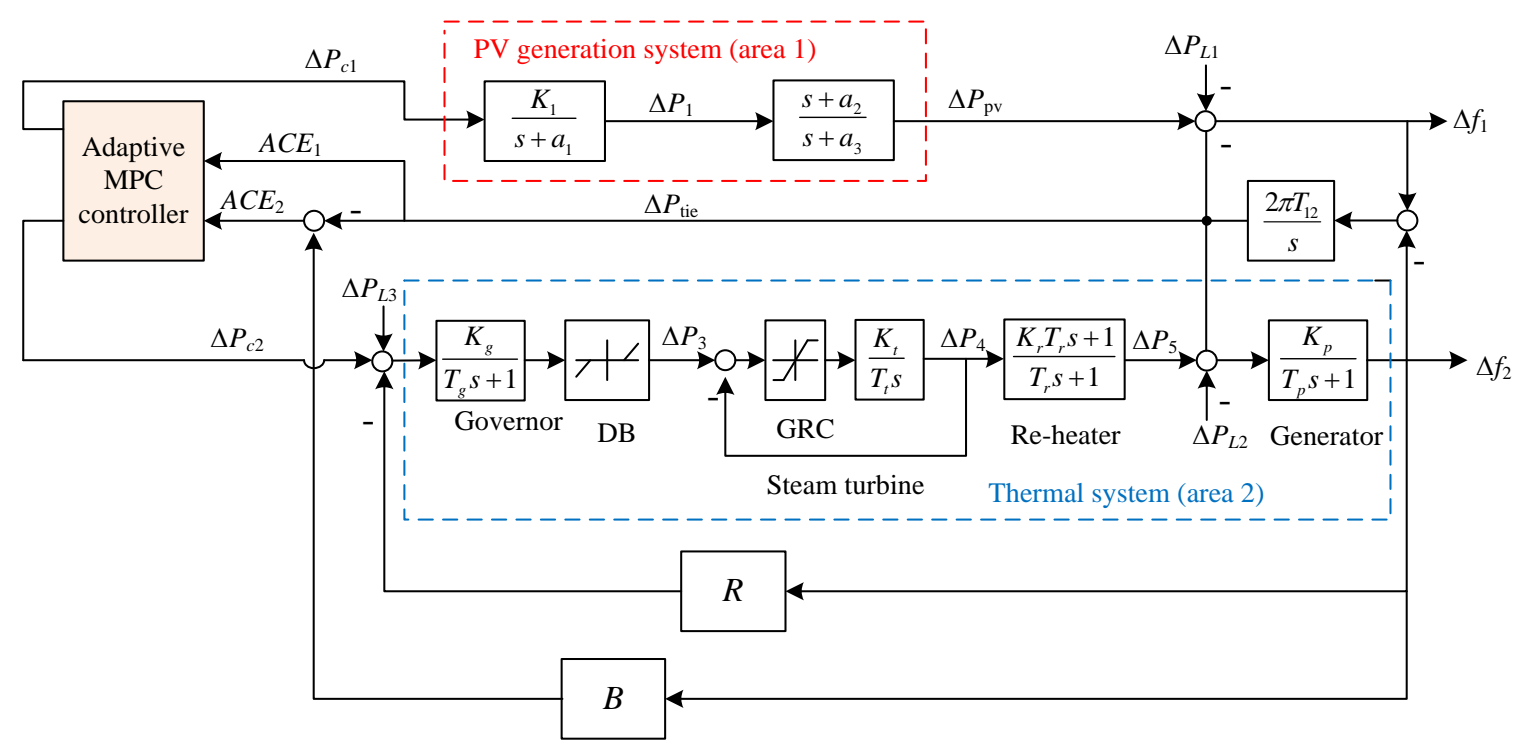

Figure 1. The block diagram of a two-area interconnected power system composed of photovoltaic and thermal generator.

For area 1, the equivalent transfer function of the PV system consisting of the PV panel, maximum power point tracking (MPPT), inverter and filter is described by the following equation [32]:

$$
G_{P V}(s)=\frac{K_{1}}{s+a_{1}} \frac{s+a_{2}}{s+a_{3}}
$$

where $K_{1}$ is the gain of PV system, $a_{1}$ and $a_{3}$ are the negative values of poles, and $a_{2}$ is the negative value of zero in transfer function.

The area control error $(A C E)$ of area 1 is defined as follows [32]:

$$
A C E_{1}(s)=\Delta P_{\text {tie }}(s)=\frac{2 \pi T_{12}\left(\Delta f_{1}(s)-\Delta f_{2}(s)\right)}{s},
$$

where $\Delta P_{\text {tie }}(s)$ is the change of tie line power (p.u.), $\Delta f_{1}$ and $\Delta f_{2}$ are the frequency deviation of area 1 and area 2 , respectively, $T_{12}$ is the synchronizing coefficient of tie line between area 1 and area 2.

Area 2 is a thermal system that consists of a governor, steam turbine, re-heater, and generator. The transfer function of governor $G_{g o}(s)$ is as follows [32]:

$$
G_{g o}(s)=\frac{K_{g}}{T_{g} s+1},
$$

where $K_{g}$ is the gain of governor, and $T_{g}$ is the first order inertial time constant of governor. 
The transfer function of steam turbine $G_{t}(s)$ is as follows [32]:

$$
G_{t}(s)=\frac{K_{t}}{T_{t} s+1},
$$

where $K_{t}$ is the gain of governor, and $T_{t}$ is the first order inertial time constant of steam turbine.

The transfer function of re-heater $G_{r}(s)$ is as follows [32]:

$$
G_{r}(s)=\frac{K_{r} T_{r} s+1}{T_{r} s+1},
$$

where $K_{r}$ is the p.u. megawatt rating of high pressure stage, and $T_{r}$ is the time constant of re-heater.

The transfer function of generator $G_{g e}(s)$ is as follows [32]:

$$
G_{g e}(s)=\frac{K_{p}}{T_{p} s+1},
$$

where $K_{p}$ is the gain of generator, and $T_{p}$ is the first order inertial time constant of generator.

For area 2, the $A C E$ is defined as follows [32]:

$$
A C E_{2}(s)=-\Delta P_{\text {tie }}(s)+B \Delta f_{2}(s),
$$

where $B$ is the biasing factor in p.u. $\mathrm{MW} / \mathrm{Hz}$.

The dynamic characteristics of the power and frequency changes in this two-area power system is reformulated as the following equations:

$$
\begin{gathered}
\Delta \dot{P}_{1}(t)=-a_{1} \Delta P_{1}(t)+K_{1} \Delta P_{c 1}(t), \\
\Delta \dot{P}_{\mathrm{pv}}(t)=\left(a_{2}-a_{1}\right) \Delta P_{1}(t)-a_{3} \Delta P_{\mathrm{pv}}(t)+K_{1} \Delta P_{c 1}(t), \\
\Delta \dot{P}_{\text {tie }}(t)=2 \pi T_{12}\left(\Delta P_{\mathrm{pv}}(t)-\Delta P_{\mathrm{tie}}(t)-\Delta f_{2}(t)-\Delta P_{L 1}(t)\right), \\
\Delta \dot{f}_{2}(t)=\frac{K_{P}}{T_{P}} \Delta P_{\text {tie }}(t)-\frac{1}{T_{P}} \Delta f_{2}(t)+\frac{K_{P}}{T_{P}} \Delta P_{5}(t)-\frac{K_{P}}{T_{P}} \Delta P_{L 2}(t), \\
\Delta \dot{P}_{3}(t)=-\frac{R}{T_{g}} \Delta f_{2}(t)-\frac{1}{T_{g}} \Delta P_{3}(t)+\frac{1}{T_{g}} \Delta P_{c 2}(t)+\frac{1}{T_{g}} \Delta P_{L 3}(t), \\
\Delta \dot{P}_{5}(t)=\frac{1}{T_{t}} \Delta P_{3}(t)-\frac{1}{T_{t}} \Delta P_{4}(t), \\
\dot{P}_{r} T_{r} T_{r} \Delta P_{3}(t)+\left(\frac{1}{T_{r}}-\frac{K_{r} T_{r}}{T_{t} T_{r}}\right) \Delta P_{4}(t)-\frac{1}{T_{r}} \Delta P_{5}(t), \\
A C E_{1}(t)=\Delta P_{\text {tie }}(t), \\
A C E_{2}(t)=-\Delta P_{\text {tie }}(t)+B \Delta f_{2}(t),
\end{gathered}
$$

where $\Delta P_{1}(t)$ is the intermediate power change of $\mathrm{PV}, \Delta P_{\mathrm{pv}}(t)$ is power change of $\mathrm{PV}, \Delta P_{\text {tie }}(t)$ is the total tie-line power change in this system, $\Delta f_{1}(t)$ and $\Delta f_{2}(t)$ are the frequency deviations of area1 and area2, respectively, $\Delta P_{3}(t), \Delta P_{4}(t)$, and $\Delta P_{5}(t)$ are the power change of governor, steam turbine, and re-heater, respectively, $\Delta P_{c 1}(t)$ and $\Delta P_{c 2}(t)$ are the control action of area1 and area2, respectively. $\Delta P_{L 1}(t), \Delta P_{L 2}(t)$, and $\Delta P_{L 3}(t)$ are the load changes, $B$ is frequency bias factor, and $R$ is the regulation constant (Hz/p.u.MW). 


\subsection{State-Space Model}

Define the state vector $\mathbf{x}(t)$, the control vector $\mathbf{u}(t)$, the disturbance vector $\mathbf{u}_{\mathbf{I}}(t)$ and system output vector $\mathbf{y}(t)$ as: $\mathbf{x}(t)=\left[\Delta P_{1}(t) \Delta P_{\mathrm{pv}}(t) \Delta P_{\text {tie }}(t) \Delta f_{2}(t) \Delta P_{3}(t) \Delta P_{4}(t) \Delta P_{5}(t)\right]^{T}, \mathbf{u}(t)=\left[\Delta P_{c 1}(t) \Delta P_{c 2}(t)\right]^{T}, \mathbf{u}_{\mathbf{I}}(t)$ $=\left[\Delta P_{L 1}(t) \Delta P_{L 2}(t) \Delta P_{L 3}(t)\right]^{T}$, and $\mathbf{y}(t)=\left[A C E_{1}(t) A C E_{2}(t)\right]^{T}$.

The state space model of the aforementioned two-area interconnected power system with $\mathrm{PV}$ generation is described as the following equations:

$$
\begin{gathered}
\frac{d \mathbf{x}(t)}{d t}=\mathbf{A x}(t)+\mathbf{u}(t)+\mathbf{B}_{\mathbf{I}} \mathbf{u}_{\mathbf{I}}(t) \\
\mathbf{y}(t)=\mathbf{C x}(t)
\end{gathered}
$$

where $\mathbf{A}, \mathbf{B}, \mathbf{B}_{\mathbf{I}}$ and $\mathbf{C}$ are parameter matrices of $\mathbf{x}(t), \mathbf{u}(t), \mathbf{u}_{\mathbf{I}}(t)$, and $\mathbf{y}(t)$, respectively.

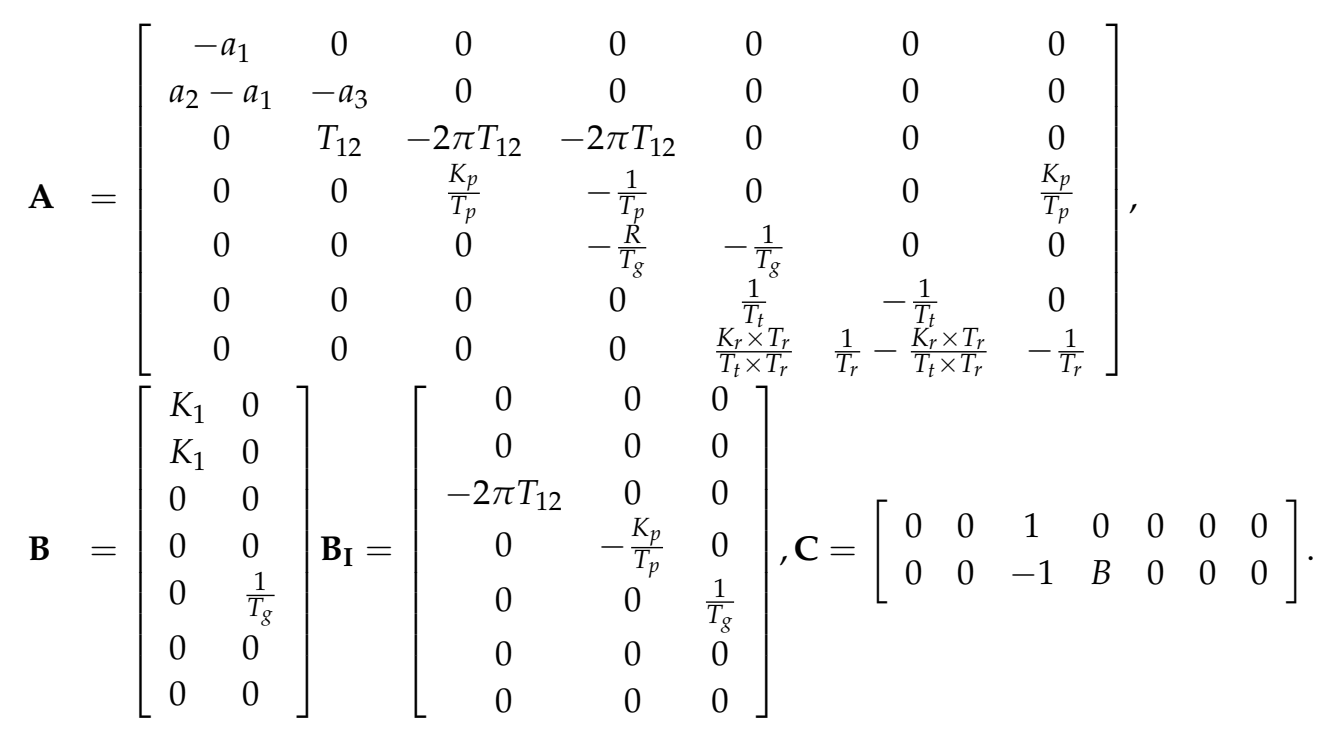

By discretization with sampling time $T_{s}$, the discrete-time state space model of (17) is obtained by the following equation:

$$
\begin{aligned}
& \mathbf{x}(k+1)=\mathbf{A}_{\mathbf{d}} \mathbf{x}(k)+\mathbf{B}_{\mathbf{d}} \mathbf{u}(k)+\mathbf{B}_{\mathbf{I d}} \mathbf{u}_{\mathbf{I}}(k), \\
& \mathbf{y}(k)=\mathbf{C} \mathbf{x}(k)
\end{aligned}
$$

where $\mathbf{x}(k+1), \mathbf{x}(k), \mathbf{u}(k), \mathbf{u}_{\mathbf{I}}(k)$, and $\mathbf{y}(k)$ are the discrete-time forms of $\mathrm{d} \mathbf{x}(t) / \mathrm{d} t, \mathbf{x}(t), \mathbf{u}(t), \mathbf{u}_{\mathbf{I}}(t)$, and $\mathbf{y}(t)$, respectively, $\mathbf{A}_{\mathbf{d}}=e^{\mathbf{A} T_{s}}, \mathbf{B}_{\mathbf{d}}=\int_{0}^{T_{s}} e^{\mathbf{A} t} \mathbf{B} d t, \mathbf{B}_{\mathbf{I d}}=\int_{0}^{T_{s}} e^{\mathbf{A} t} \mathbf{B}_{\mathbf{I}} d t$.

The incremental form of Equation (18) is defined as follows:

$$
\begin{aligned}
& \Delta \mathbf{x}(k+1)=\mathbf{A}_{\mathbf{d}} \Delta \mathbf{x}(k)+\mathbf{B}_{\mathbf{d}} \Delta \mathbf{u}(k)+\mathbf{B}_{\mathbf{I d}} \Delta \mathbf{u}_{\mathbf{I}}(k) \\
& \Delta \mathbf{y}(k)=\mathbf{C} \Delta \mathbf{x}(k)
\end{aligned}
$$

where $\Delta \mathbf{x}(k+1), \Delta \mathbf{x}(k), \Delta \mathbf{u}(k), \Delta \mathbf{u}_{\mathbf{I}}(k)$, and $\Delta \mathbf{y}(k)$ are the incremental forms of $\mathbf{x}(k+1), \mathbf{x}(k), \mathbf{u}(k), \mathbf{u}_{\mathbf{I}}(k)$, and $\mathbf{y}(k)$, respectively.

\section{The Proposed Method}

In this section, we present an adaptive model predictive load frequency control method for a multi-area interconnected power system with PV generation. The key idea behind the proposed method is obtaining the dynamic predictive model by introducing an expanded state vector, and rolling optimization of control signal vectors based on a cost function by minimizing the weighted sum of square predicted errors and square future control values. 
By defining an extend state vector $\mathbf{Z}(k)=(\Delta \mathbf{x}(k) \mathbf{y}(k-1))^{T}$, the following expanded discrete-time state space model is reformulated according to the Equations (18) and (19):

$$
\begin{aligned}
& \mathbf{Z}(k+1)=\mathbf{G Z}(k)+\mathbf{H} \Delta \mathbf{u}(k)+\mathbf{H}_{\mathbf{I}} \Delta \mathbf{u}_{\mathbf{I}}(k) \\
& \mathbf{y}(k)=\mathbf{C}_{\mathbf{Z}} \mathbf{Z}(k)
\end{aligned}
$$

where $\mathbf{G}=\left(\begin{array}{cc}\mathbf{A}_{\mathbf{d}} & \mathbf{0}_{N_{x} \times N_{y}} \\ \mathbf{C} & \mathbf{E}_{N_{y}}\end{array}\right)_{\left(N_{x}+N_{y}\right) \times\left(N_{x}+N_{y}\right)}, \mathbf{H}=\left(\begin{array}{c}\mathbf{B}_{\mathbf{d}} \\ \mathbf{0}_{N_{y} \times N_{u}}\end{array}\right)_{\left(N_{x}+N_{y}\right) \times N_{u}}, \quad \mathbf{H}_{\mathbf{I}}=$ $\left(\begin{array}{c}\mathbf{B}_{\mathbf{I d}} \\ \mathbf{0}_{N_{y} \times N_{u I}}\end{array}\right)_{\left(N_{x}+N_{y}\right) \times N_{u I}}, \mathbf{C}_{\mathbf{z}}=\left(\begin{array}{ll}\mathbf{C} & \mathbf{E}_{N_{y}}\end{array}\right)_{N_{y} \times\left(N_{x}+N_{y}\right)}, \mathbf{E}_{N_{y}}$ is an identity matrix with $N_{y}$ rows and $N_{y}$ columns, $\mathbf{0}_{N_{x} \times N_{y}}$ is a zero matrix with $N_{x}$ rows and $N_{y}$ columns, $N_{x}, N_{y}, N_{u}$ and $N_{u I}$ are the states number of $\mathbf{x}(t), \mathbf{y}(t), \mathbf{u}(t)$ and $\mathbf{u}_{\mathbf{I}}(t)$, respectively.

The predictive output value $\mathbf{y}(k+p \mid k)$ at $k$-th sample time is calculated as follows:

$$
\mathbf{y}(k+p \mid k)=\mathbf{C}_{\mathbf{z}} \mathbf{G}^{p} \mathbf{Z}(k)+\sum_{j=1}^{p} \mathbf{C}_{\mathbf{Z}} \mathbf{G}^{p-j} \mathbf{H} \Delta \mathbf{u}(k+j-1)+\sum_{j=1}^{p} \mathbf{C}_{\mathbf{z}} \mathbf{G}^{p-j} \mathbf{H}_{\mathbf{I}} \Delta \mathbf{u}_{\mathbf{I}}(k+j-1), p=1,2, \cdots, P,
$$

where $P$ is prediction horizon, and $M$ is the control horizon.

The predictive output vector $\mathbf{Y}_{\mathbf{P}}(k)$ is evaluated as follows:

$$
\mathbf{Y}_{\mathbf{P}}(k)=\phi \mathbf{Z}(k)+\psi \Delta \mathbf{U}(k)+\psi_{I} \Delta \mathbf{U}_{\mathbf{I}}(k),
$$

where each vector is defined as follows:

$$
\begin{aligned}
& \mathbf{Y}_{\mathbf{P}}(k)=\left(\begin{array}{c}
\mathbf{y}(k+1 \mid k) \\
\ldots \\
\mathbf{y}(k+P \mid k)
\end{array}\right)_{\left(P \times N_{y}\right) \times 1}, \Delta \mathbf{U}(k)=\left(\begin{array}{c}
\Delta \mathbf{u}(k) \\
\cdots \\
\Delta \mathbf{u}(k+P-1)
\end{array}\right)_{\left((P-1) \times N_{u}\right) \times 1}, \Delta \mathbf{U}_{\mathbf{I}}(k)=\left(\begin{array}{c}
\Delta \mathbf{u}_{\mathbf{I}}(k) \\
\cdots \\
\Delta \mathbf{u}_{\mathbf{I}}(k+P-1)
\end{array}\right)_{\left((P-1) \times N_{u l}\right) \times 1}, \\
& \phi=\left(\begin{array}{c}
\mathrm{C}_{\mathbf{z}} \mathrm{G} \\
\mathrm{C}_{\mathbf{z}} \mathrm{G}^{2} \\
\vdots \\
\mathrm{C}_{\mathbf{z}} \mathrm{G}^{P}
\end{array}\right)_{\left(P \times N_{y}\right) \times\left(N_{x}+N_{y}\right)}, \\
& \psi=\left(\begin{array}{cccc}
\mathbf{C}_{\mathbf{z}} \mathbf{H} & \mathbf{0}_{N_{u}} & \cdots & \mathbf{0}_{N_{u}} \\
\mathrm{C}_{\mathbf{z}} \mathbf{G H} & \mathrm{C}_{\mathbf{z}} \mathbf{H} & \cdots & \mathbf{0}_{N_{u}} \\
\vdots & \vdots & \vdots & \vdots \\
\mathrm{C}_{\mathbf{z}} \mathrm{G}^{P-1} \mathbf{H} & \mathrm{C}_{\mathbf{z}} \mathrm{G}^{P-2} \mathbf{H} & \cdots & \mathrm{C}_{\mathbf{z}} \mathbf{H}
\end{array}\right)_{\left(P \times N_{y}\right) \times\left((P-1) \times N_{u}\right)}, \\
& \psi_{I}=\left(\begin{array}{cccc}
\mathrm{C}_{\mathbf{z}} \mathbf{H}_{\mathbf{I}} & \mathbf{0}_{N_{u I}} & \cdots & \mathbf{0}_{N_{u I}} \\
\mathbf{C}_{\mathbf{z}} \mathbf{G H}_{\mathbf{I}} & \mathrm{C}_{z} \mathbf{H}_{\mathbf{I}} & \cdots & \mathbf{0}_{N_{u I}} \\
\vdots & \vdots & \vdots & \vdots \\
\mathbf{C}_{\mathbf{z}} \mathbf{G}^{P-1} \mathbf{H}_{\mathbf{I}} & \mathbf{C}_{\mathbf{z}} \mathbf{G}^{P-2} \mathbf{H}_{\mathbf{I}} & \cdots & \mathbf{C}_{\mathbf{z}} \mathbf{H}_{\mathbf{I}}
\end{array}\right)_{\left(P \times N_{y}\right) \times\left((P-1) \times N_{u I}\right)} .
\end{aligned}
$$

Based on the research results [33], the reference trajectory $\mathbf{y}_{\mathbf{r}}(k+p \mid k)$ is defined as follows:

$$
\mathbf{y}_{\mathbf{r}}(k+p \mid k)=\lambda^{p} \mathbf{y}(k)+\left(1-\lambda^{p}\right) \mathbf{c}(k), p=1, \ldots P,
$$

where $\lambda$ is a soften factor, and $\mathbf{c}(k)$ is the set value of system output. The vector form of Equation (23) is redefined as follows:

$$
\mathbf{Y}_{\mathbf{r}}(k)=\left(\begin{array}{c}
\mathbf{y}_{\mathbf{r}}(k+1 \mid k) \\
\cdots \\
\mathbf{y}_{\mathbf{r}}(k+P \mid k)
\end{array}\right)_{\left(P \times N_{y}\right) \times 1}
$$

The optimal load-frequency control issue of a multi-area power system with PV generation is formulated as a typical constrained MPC problem:

$$
\min J(k)=\min \left\{\left(\mathbf{Y}_{\mathbf{P}}(k)-\mathbf{Y}_{\mathbf{r}}(k)\right)^{T} \mathbf{Q}\left(\mathbf{Y}_{\mathbf{P}}(k)-\mathbf{Y}_{\mathbf{r}}(k)\right)+(\Delta \mathbf{U}(k))^{T} \mathbf{R}(\Delta \mathbf{U}(k))\right\},
$$




$$
\begin{gathered}
\text { s.t.Equations (22)-(24) } \\
\mathbf{u}_{\min } \leq \mathbf{u}(k) \leq \mathbf{u}_{\max } \\
\Delta \mathbf{u}_{\min } \leq \Delta \mathbf{u}(k) \leq \Delta \mathbf{u}_{\max } \\
\mathbf{y}_{\min } \leq \mathbf{y}(k) \leq \mathbf{y}_{\max }
\end{gathered}
$$

where $\mathbf{Q}$ and $\mathbf{R}$ are the weighting vectors to balance the performance of square predicted errors and square future control values, $\mathbf{u}_{\min }$ and $\mathbf{u}_{\max }$ are the lower and upper limits of the control signal vector $\mathbf{u}(k)$, respectively, $\Delta \mathbf{u}_{\min }$ and $\Delta \mathbf{u}_{\max }$ are the lower and upper limits of the increment of the control signal vector $\Delta \mathbf{u}(k)$, respectively, $\mathbf{y}_{\min }$ and $\mathbf{y}_{\max }$ are the lower and upper limits of the system output $\mathbf{y}(k)$, respectively. In general, $\mathbf{Q}$ and $\mathbf{R}$ can be determined by some empirical rules, and trial and error [33].

According to the gradient descent method, i.e., $\frac{\partial J(k)}{\Delta \mathbf{U}(k)}=0$, the control law $\mathbf{u}(k)$ is obtained by the following equations:

$$
\begin{aligned}
& \Delta \mathbf{U}(k)=\left(\psi^{T} \mathbf{Q} \psi+R\right)^{-1} \psi^{T} \mathbf{Q}\left(\mathbf{Y}_{r}(k)-\phi \mathbf{Z}(k)-\psi_{I} \Delta \mathbf{U}_{\mathbf{I}}(k)\right), \\
& \Delta \mathbf{u}(k)=\left(\begin{array}{ll}
E_{N_{u}} & \mathbf{0}_{N_{u} \times(P-1)}
\end{array}\right) \Delta \mathbf{U}(k), \\
& \mathbf{u}(k)=\Delta \mathbf{u}(k)+\mathbf{u}(k-1) .
\end{aligned}
$$

Based on the above analysis, Figure 2 presents the detailed structure of the proposed MPC method for LFC of a multi-area interconnected power system with PV generation. The flowchart of MPC is shown in Figure 3, and the detailed steps are summarized as follows:

Step 1: Import the discrete time state space model of a multi-area interconnected power system with PV generation described as Equations (18) and (19).

Step 2: Obtain the expanded state space model described as Equation (20) by introducing an expanded state vector.

Step 3: Initialize the parameters of predictive control model including maximum number of sampling $T_{\text {max }}$, prediction domain $P$, control domain $M$, weighting vectors $\mathbf{Q}$ and $\mathbf{R}$, and set $k=1$;

Step 4: For the current time $k$, obtain the past values of the output vector $\mathbf{y}(k-1)=\left[A C E_{1}(k-1)\right.$, $\left.A C E_{2}(k-1)\right]^{T}$, control vector $\mathbf{u}(k-1)=\left[\Delta P_{c 1}(k-1), \Delta P_{c 2}(k-1)\right]^{T}$, state vector $\mathbf{x}(k-1)=$ $\left[\Delta P_{1}(k-1), \Delta P_{\mathrm{pv}}(k-1), \Delta P_{\text {tie }}(k-1), \Delta f_{2}(k-1), \Delta P_{3}(k-1), \Delta P_{4}(k-1), \Delta P_{5}(k-1)\right]^{T}$, and disturbance vector $\mathbf{u}_{\mathbf{I}}(k-1)=\left[\Delta P_{L 1}(k-1), \Delta P_{L 2}(k-1), \Delta P_{L 3}(k-1)\right]^{T}$.

Step 5: Obtain the predictive vector $\mathbf{Y}_{\mathbf{P}}(k)$ by Equation (22) and the rolling optimization model consisting of cost function (25) and constraints (26).

Step 6: Obtain the optimal control vector $\mathbf{u}(k)$ according to Equations (27)-(29) by gradient descent method.

Step 7: Compute the optimal system output $\mathbf{y}(k)$ and state vector $\mathbf{x}(k)$ under $\mathbf{u}(k)$.

Step 8: Set $k=k+1$, and return step 4 until $k=T_{\max }$.

Step 9: Obtain the system output $\left\{\mathbf{y}(k), k=1,2, \ldots, T_{\max }\right\}$, frequency deviation $\left\{\Delta f_{1}(k), \Delta f_{2}(k), k=1\right.$, $\left.2, \ldots, T_{\max }\right\}$, and tie line power $\left\{\Delta P_{\text {tie }}(k), k=1,2, \ldots, T_{\max }\right\}$ of a multi-area interconnected power system with $P V$ generation. 


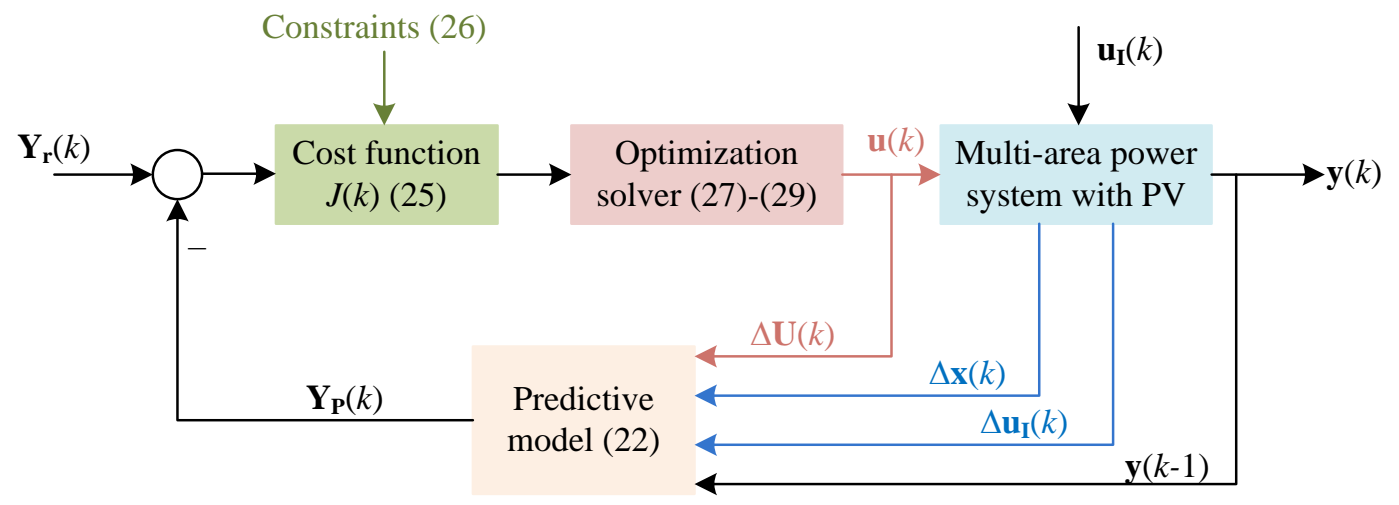

Figure 2. The structure of MPC method for the optimal LFC issue of a multi-area interconnected power system with PV generation.

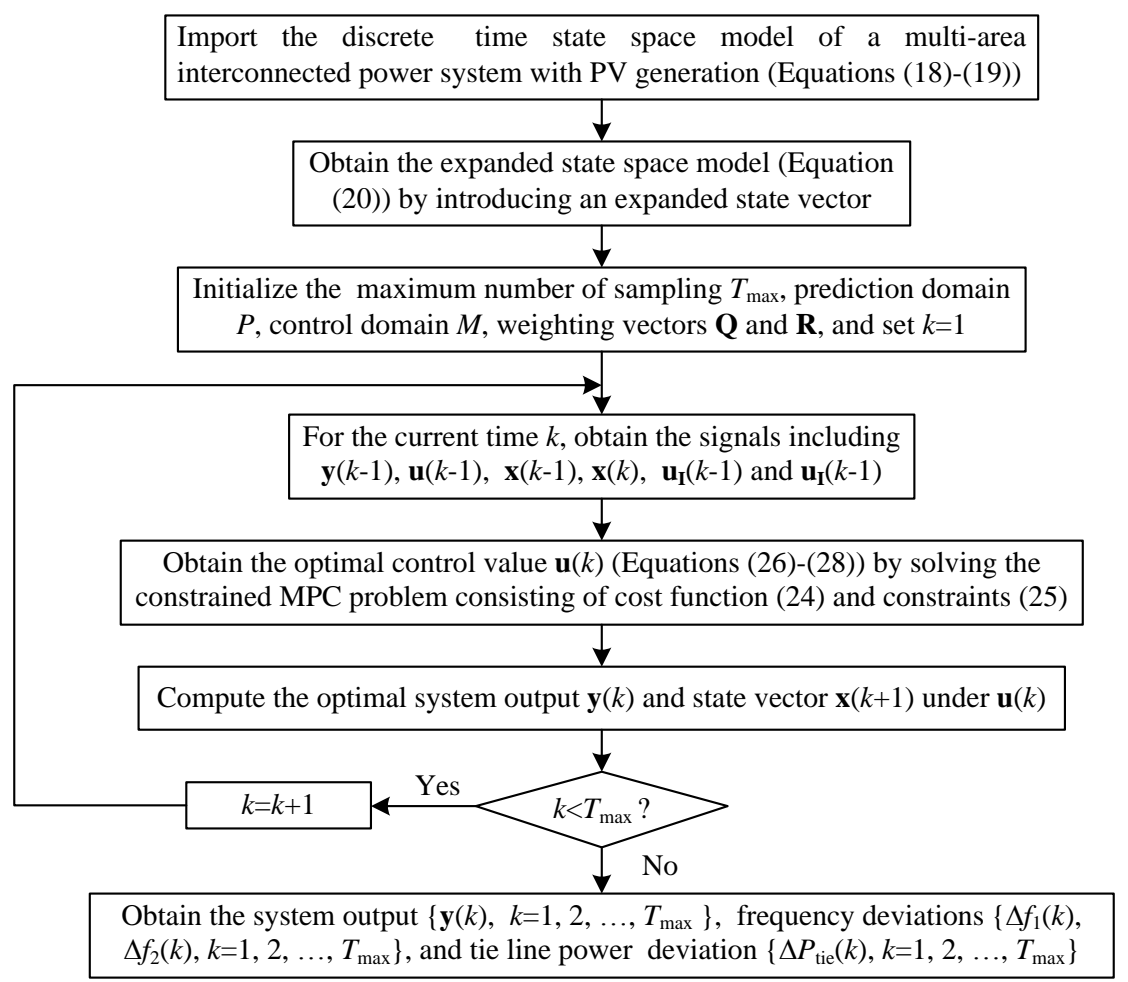

Figure 3. The flowchart of MPC for LFC of a multi-area interconnected power system with PV generation.

\section{Simulation Results}

In order to demonstrate the effectiveness of the proposed MPC method, this section presents the simulation results on a two-area interconnected power system with PV generation. The system parameters are set as: $T_{p}=20 \mathrm{~s}, T_{t}=0.3 \mathrm{~s}, T_{r}=10 \mathrm{~s}, T_{12}=0.545$ p.u., $T_{\mathrm{g}}=0.08 \mathrm{~s}, K_{P}=120 \mathrm{~Hz} / \mathrm{p} . \mathrm{u}$. MW, $K_{g}=K_{t}=1 \mathrm{~Hz} /$ p.u.MW, $K_{r}=3.3 \mathrm{~Hz} /$ p.u MW, $B=0.8$ p.u.MW $/ \mathrm{Hz}, R=0.4 \mathrm{~Hz} /$ p.u.MW, $K_{r 1}=$ 0.33 p.u. MW, $a_{1}=99.5, a_{3}=0.5, a_{2}=-50, K_{1}=-18$. According to the previous research work [44,45], the maximum value of DB for governor is set as 0.05 p.u., and the GRC value is specified as $10 \%$ per minute.

The comparative methods include firefly algorithm (FA)-based PI controller abbreviated as FA-PI [32], genetic algorithm (GA)-based PI controller abbreviated as GA-PI [32], and our recently reported population extremal optimization (PEO)-based PI controller abbreviated as PEO-PI [42,43]. 
For fair comparison, the lower and upper limits of the optimized PI controllers' parameters are set as -2 and 2 for FA-PI, GA-PI and PEO-PI, respectively [32]. The parameters setting of MPC and three mentioned evolutionary algorithms based PI methods are shown in Table 1 . Table 2 presents four experimental conditions and all the following simulations is implemented on by MATLAB $2012 \mathrm{~b}$ software on a $2.50 \mathrm{GHz}$ PC with i7-3537U processor and 4 GB RAM.

Table 1. The parameters setting of MPC, PEO-PI, GA-PI and FA-PI.

\begin{tabular}{cc}
\hline Algorithm & Parameters Setting \\
\hline FA-PI [32] & $\begin{array}{r}\text { Number of fireflies }=50, \text { maximum number of generations }=100, \text { the contrast of the } \\
\text { attractiveness }=1.0, \text { the attractiveness }=0.1 \text { at } r=0, \text { randomization }=0.1 .\end{array}$ \\
\hline GA-PI [32] & $\begin{array}{r}\text { Population size }=50, \text { maximum number of generations }=100, \text { the crossover probability } \\
p_{c}=0.75, \text { the mutation probability } p_{\mathrm{m}}=0.1 .\end{array}$ \\
\hline PEO-PI [43] & $\begin{array}{c}\text { Population size }=30, \text { maximum number of generations }=100, \text { shape parameter of MNUM } \\
\text { mutation } b=2 .\end{array}$ \\
\hline MPC & Prediction horizon $P=15, \begin{array}{c}\text { control horizon } M=10, \text { weight vectors } \mathbf{Q}=E_{P \times P}, \\
\mathbf{R}=0.01 E_{M \times M .} .\end{array}$ \\
\hline
\end{tabular}

Table 2. Theconditions of experiments.

\begin{tabular}{cc}
\hline Experiment & Condition \\
\hline Case 1 & Step increase in demand of thermal system, i.e., $\Delta P_{L 1}=0.1$ \\
Case 2 & Step increase in demand of thermal system and PV generation, i.e., $\Delta P_{L 1}=0.1$ \\
Case 3 & and $\Delta P_{L 2}=0.1$ \\
Case 4 & Parameter $T_{g}$ increases and decreases $40 \%$ under $\Delta P_{L 1}=0.1$ and $\Delta P_{L 2}=0.1$ \\
Case 5 & Parameter $T_{t}$ increases and decreases $40 \%$ under $\Delta P_{L 1}=0.1$ and $\Delta P_{L 2}=0.1$ \\
Case 6 & Dynamical fluctuations of $\Delta P_{L 1}$ \\
\hline
\end{tabular}

\subsection{Case 1: Step Increase in Demand of Thermal System}

Table 3 presents the optimized PI parameters including $K_{\mathrm{P} 1}, K_{\mathrm{I} 1}, K_{\mathrm{P} 2}$, and $K_{\mathrm{I} 2}$ obtained by PEO-PI, GA-PI and FA-PI for case 1. Frequency deviations $\Delta f_{1}, \Delta f_{2}$, and tie line power deviation $\Delta P_{\text {tie }}$ obtained by MPC, PEO-PI, GA-PI and FA-PI for case 1 are shown in Figure 4 and the corresponding performance of is compared in Table 4. The performance indices include the integral of absolute value of the error $(I A E)$, the integral of time multiplied absolute value of the error (ITAE), the integral of square error (ISE), the integral of time multiplied square error (ITSE), the overshoot of $\Delta f_{1}, \Delta f_{2}$ and $\Delta P_{\text {tie }}$ denoted as $_{p 1}, M_{p 2}$ and $M_{p 3}$,respectively, the rising time of $\Delta f_{1}, \Delta f_{2}$ and $\Delta P_{\text {tie }}$ denoted as $t_{r 1}, t_{r 2}$ and $t_{r 3}$, respectively, settling time of $\Delta f_{1}, \Delta f_{2}$ and $\Delta P_{\text {tie }}$ denoted as $t_{s 1}, t_{s 2}$ and $t_{s 3}$, respectively, the steady-state error of $\Delta f_{1}, \Delta f_{2}$ and $\Delta P_{\text {tie }}$ denoted as $E_{s s 1}, E_{s s 2}$ and $E_{s s 3}$, respectively. More specifically, IAE, ITAE, ISE and ITSE are defined as follows [32]:

$$
\begin{gathered}
\text { IAE }=\int_{0}^{T_{\max }}\left(\left|\Delta f_{1}\right|+\left|\Delta f_{2}\right|+\left|\Delta P_{\text {tie }}\right|\right) d t, \\
\text { ITAE }=\int_{0}^{T_{\max }} t\left(\left|\Delta f_{1}\right|+\left|\Delta f_{2}\right|+\left|\Delta P_{\text {tie }}\right|\right) d t, \\
\text { ISE }=\int_{0}^{T_{\max }}\left(\left(\Delta f_{1}\right)^{2}+\left(\Delta f_{2}\right)^{2}+\left(\Delta P_{\text {tie }}\right)^{2}\right) d t, \\
\text { ITSE }=\int_{0}^{T_{\max }} t\left(\left(\Delta f_{1}\right)^{2}+\left(\Delta f_{2}\right)^{2}+\left(\Delta P_{\text {tie }}\right)^{2}\right) d t .
\end{gathered}
$$


Table 3. Optimized PI parameters obtained by PEO-PI, GA-PI and FA-PI.

\begin{tabular}{ccccc}
\hline Algorithm & $\boldsymbol{K}_{\mathbf{P 1}}$ & $\boldsymbol{K}_{\mathbf{I 1}}$ & $\boldsymbol{K}_{\mathbf{P 2}}$ & $\boldsymbol{K}_{\mathbf{I 2}}$ \\
\hline FA-PI [32] & -0.8811 & -0.5765 & -0.7626 & -0.8307 \\
GA-PI [32] & -0.5663 & -0.4024 & -0.5127 & -0.7256 \\
PEO-PI [43] & -0.8749 & -0.1373 & -1.999 & -1.9487 \\
\hline
\end{tabular}

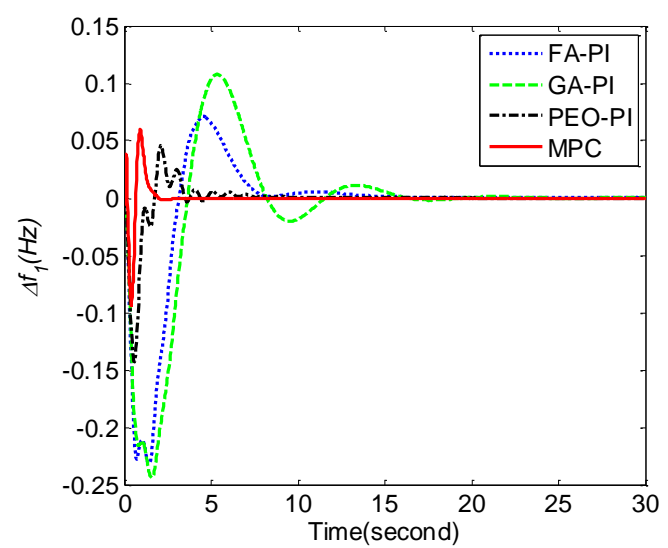

(a)

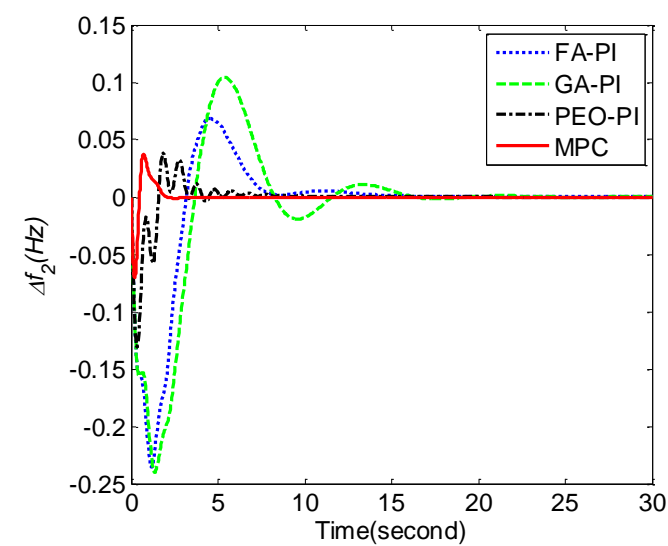

(b)

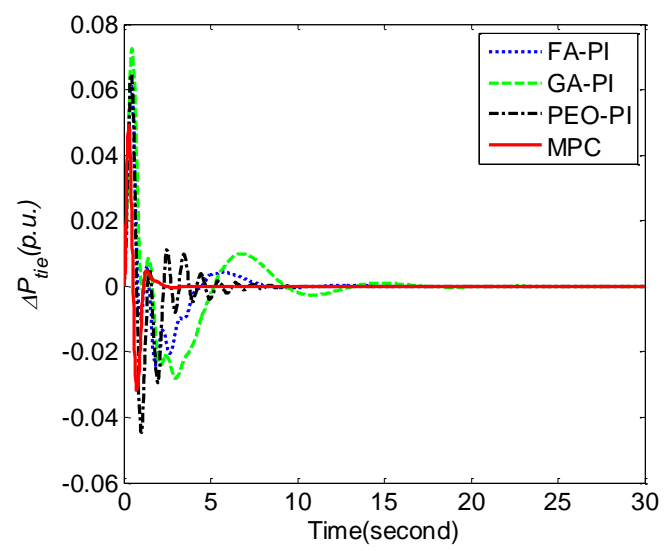

(c)

Figure 4. Comparison of frequency deviations $\Delta f_{1}, \Delta f_{2}$, and tie line power deviation $\Delta P_{\text {tie }}$ obtained by different control methods for case 1. (a) frequency deviation $\Delta f_{1} ;$ (b) frequency deviation $\Delta f_{2} ;$ (c) tie line power deviation $\Delta P_{\text {tie. }}$.

From Table 4, it is clear that MPC performs better than FA-PI, GA-PI and PEO-PI in the terms of all of the performance indices.

\subsection{Case 2: Step Increase in Demand of Thermal System and PVGeneration}

For case 2, the frequency deviations $\Delta f_{1}, \Delta f_{2}$, and tie line power deviation $\Delta P_{\text {tie }}$ obtained by MPC, PEO-PI, GA-PI and FA-PI under $\Delta P_{L 1}=0.1$ and $\Delta P_{L 2}=0.1$ are shown in Figure 5 and the corresponding performance indices of are compared in Table 5. Obviously, all of the indices obtained by MPC are the best among the four methods. 
Table 4. Performance comparison of MPC, PEO-PI, GA-PI and FA-PI for case 1.

\begin{tabular}{ccccccccccccccccc}
\hline Algorithm & IAE & ITAE & ISE & ITSE & $\boldsymbol{M}_{\boldsymbol{p} \mathbf{1}}$ & $\boldsymbol{t}_{\boldsymbol{u} \mathbf{1}}$ & $\boldsymbol{t}_{\boldsymbol{s} \mathbf{1}}$ & $\boldsymbol{E}_{\boldsymbol{s \boldsymbol { 1 } 1}}$ & $\boldsymbol{M}_{\boldsymbol{p} \mathbf{2}}$ & $\boldsymbol{t}_{\boldsymbol{u} \mathbf{2}}$ & $\boldsymbol{t}_{\boldsymbol{s} \mathbf{2}}$ & $\boldsymbol{E}_{\boldsymbol{s s} \mathbf{2}}$ & $\boldsymbol{M}_{\boldsymbol{p} \mathbf{3}}$ & $\boldsymbol{t}_{\boldsymbol{u} \mathbf{3}}$ & $\boldsymbol{t}_{\boldsymbol{s} \mathbf{3}}$ & $\boldsymbol{E}_{\boldsymbol{s s} \mathbf{3}}$ \\
\hline FA-PI & 41.38 & 117.76 & 5.29 & 8.83 & 0.07 & 3.12 & 11.75 & $1.89 \times 10^{-5}$ & 0.07 & 3.15 & 11.71 & $2.22 \times 10^{-5}$ & 0.06 & 3.85 & 3.85 & $5.68 \times 10^{-7}$ \\
GA-PI & 59.32 & 227.11 & 7.60 & 18.03 & 0.11 & 3.61 & 15.11 & $1.30 \times 10^{-4}$ & 0.10 & 3.63 & 15.11 & $1.02 \times 10^{-4}$ & 0.07 & 4.83 & 8.28 & $5.87 \times 10^{-6}$ \\
PEO-PI & 11.07 & 19.80 & 0.63 & 0.49 & 0.05 & 1.73 & 5.22 & $1.34 \times 10^{-5}$ & 0.04 & 1.57 & 5.92 & $1.18 \times 10^{-5}$ & 0.06 & 1.34 & 3.67 & $1.09 \times 10^{-5}$ \\
MPC & 8.83 & 6.07 & 0.39 & 0.20 & 0.06 & 0.67 & 1.68 & $3.05 \times 10^{-6}$ & 0.04 & 0.47 & 1.73 & $1.13 \times 10^{-7}$ & 0.05 & 1.08 & 1.32 & $4.63 \times 10^{-8}$ \\
\hline
\end{tabular}

Table 5. Performance comparison of MPC, PEO-PI, GA-PI and FA-PI for case 2.

\begin{tabular}{|c|c|c|c|c|c|c|c|c|c|c|c|c|c|c|c|c|}
\hline Algorithm & IAE & ITAE & ISE & ITSE & $M_{p_{1}}$ & $t_{u_{1}}$ & $t_{s_{1}}$ & $E_{s s_{1}}$ & $M_{p_{2}}$ & $t_{u_{2}}$ & $t_{s_{2}}$ & $E_{s s_{2}}$ & $M_{p_{3}}$ & $t_{u_{3}}$ & $t_{s_{3}}$ & $E_{s s_{3}}$ \\
\hline FA-PI & 42.99 & 114.54 & 5.77 & 8.69 & 0.07 & 2.94 & 11.67 & $1.98 \times 10^{-5}$ & 0.07 & 3.07 & 11.64 & $2.17 \times 10^{-5}$ & 0.06 & 3.84 & 3.84 & $5.08 \times 10^{-7}$ \\
\hline GA-PI & 60.80 & 221.79 & 8.29 & 17.81 & 0.11 & 3.43 & 14.95 & $1.07 \times 10^{-4}$ & 0.11 & 3.5 & 14.97 & $9.82 \times 10^{-5}$ & 0.07 & 4.63 & 8.14 & $7.70 \times 10^{-6}$ \\
\hline PEO-PI & 21.27 & 86.77 & 1.66 & 1.21 & 0.06 & 1.17 & 4.91 & $7.84 \times 10^{-4}$ & 0.05 & 1.66 & 5.55 & $7.89 \times 10^{-4}$ & 0.06 & 1.53 & 7.19 & $6.29 \times 10^{-4}$ \\
\hline MPC & 11.25 & 7.01 & 0.63 & 0.27 & 0.07 & 0.23 & 1.75 & $5.11 \times 10^{-6}$ & 0.05 & 0.49 & 1.78 & $1.13 \times 10^{-7}$ & 0.05 & 1.10 & 1.48 & $4.63 \times 10^{-8}$ \\
\hline
\end{tabular}




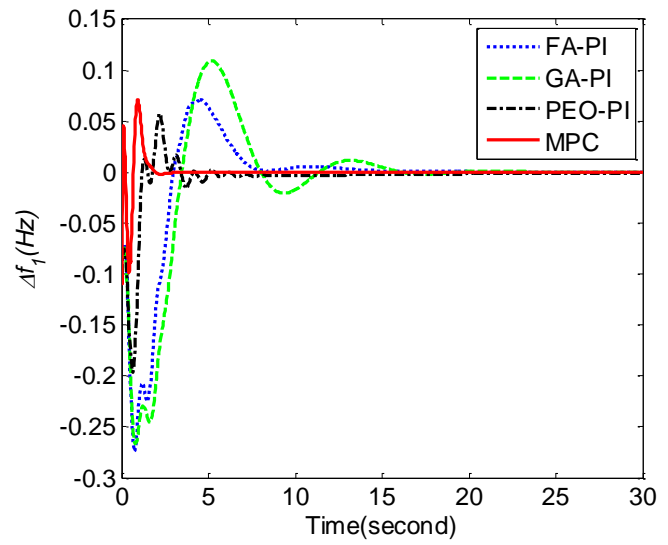

(a)

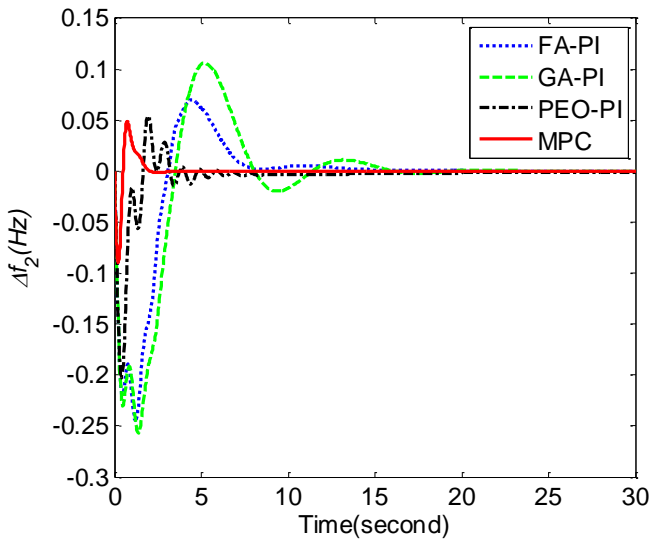

(b)

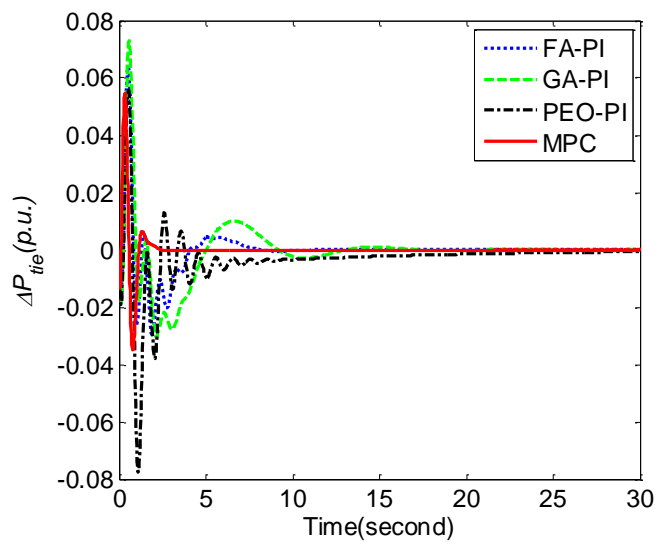

(c)

Figure 5. Comparison of frequency deviations $\Delta f_{1}, \Delta f_{2}$, and tie line power deviation $\Delta P_{\text {tie }}$ obtained by different control methods for case 2. (a) frequency deviation $\Delta f_{1}$; (b) frequency deviation $\Delta f_{2}$; (c) tie line power deviation $\Delta P_{\text {tie }}$

\subsection{Case 3: Robustness Test for Perturbed Parameter $T_{g}$}

In order to demonstrate the robustness of the proposed method against parameters uncertainty, the experiments have been implemented when parameter $T_{g}$ increases and decreases $40 \%$ under $\Delta P_{L 1}=0.1$ and $\Delta P_{L 2}=0.1$. Table 6 presents the performance comparison under two conditions including $T_{g}$ increasing $40 \%$ and decreasing $40 \%$. Clearly, MPC performs the best in terms of IAE, ITAE, ISE and ITSE under all of the conditions. Furthermore, the dynamic responses of the frequency deviations $\Delta f_{1}, \Delta f_{2}$, and tie line power deviation $\Delta P_{\text {tie }}$ obtained by MPC, PEO-PI, GA-PI and FA-PI under $T_{g}$ increasing $40 \%$ and decreasing $40 \%$ are shown in Figures 6 and 7, respectively. MPC obtained less fluctuations, faster responses and better steady-state performance than PEO-PI, GA-PI and FA-PI when parameter $T_{g}$ mismatches.

Table 6. Performance comparison of MPC, PEO-PI, GA-PI and FA-PI for case 3.

\begin{tabular}{cccccc}
\hline Algorithm & Condition & IAE & ITAE & ISE & ITSE \\
\hline FA-PI [32] & & 43.36 & 113.56 & 6.01 & 9.04 \\
GA-PI [32] & $T_{g}$ increases & 62.65 & 225.38 & 8.72 & 18.81 \\
PEO-PI [43] & $40 \%$ & 19.93 & 62.22 & 1.66 & 1.24 \\
MPC & & 10.97 & 7.38 & 0.66 & 0.33 \\
\hline FA-PI [32] & & 42.38 & 112.71 & 5.65 & 8.55 \\
GA-PI [32] & $T_{g}$ decreases & 60.54 & 213.73 & 8.22 & 17.48 \\
PEO-PI [43] & $40 \%$ & 19.3 & 60.93 & 1.53 & 1.11 \\
MPC & & 10.21 & 6.60 & 0.58 & 10.26 \\
\hline
\end{tabular}




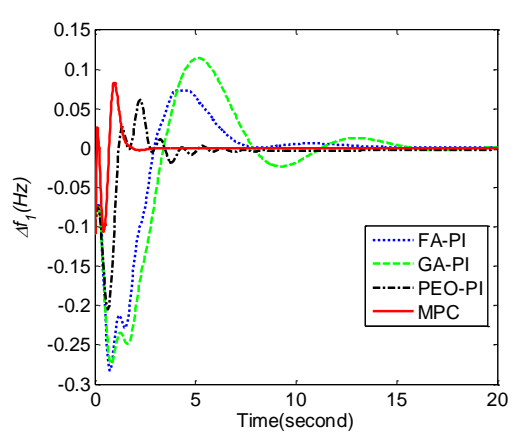

(a)

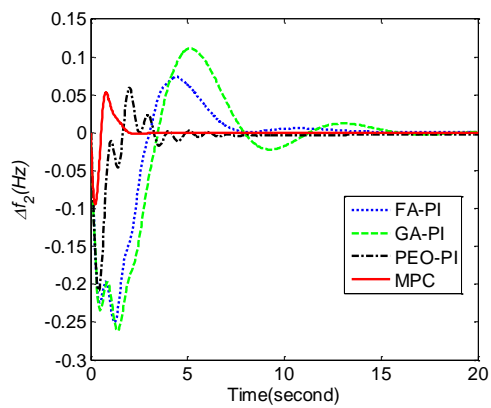

(b)

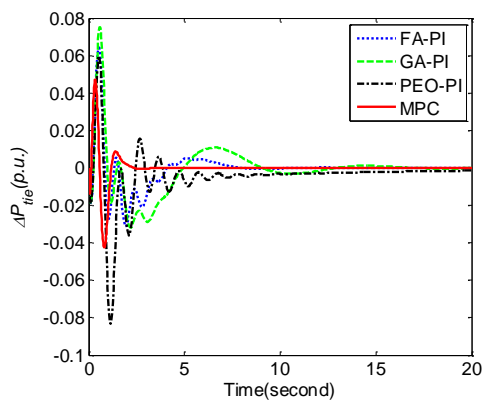

(c)

Figure 6. Comparison of frequency deviations $\Delta f_{1}, \Delta f_{2}$, and tie line power deviation $\Delta P_{\text {tie }}$ obtained by different control methods under $T_{g}$ increasing $40 \%$ for case 3. (a) frequency deviation $\Delta f_{1}$; (b) frequency deviation $\Delta f_{2} ;(\mathbf{c})$ tie line power deviation $\Delta P_{\text {tie }}$.

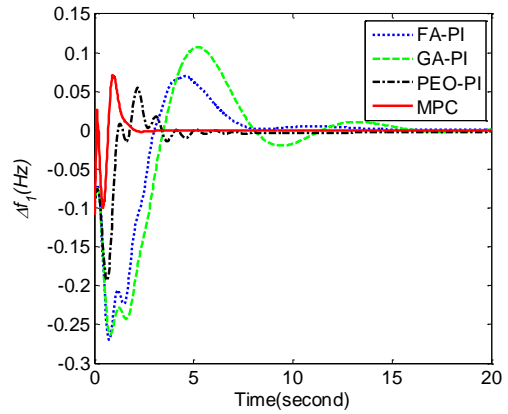

(a)

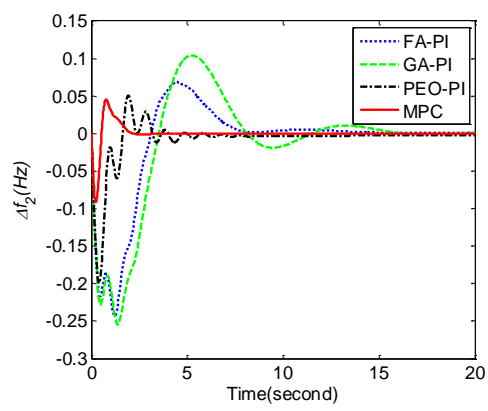

(b)

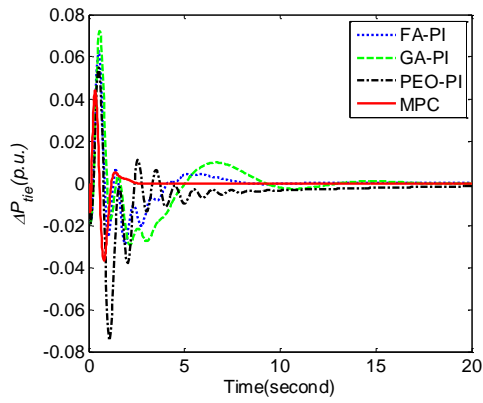

(c)

Figure 7. Comparison of frequency deviations $\Delta f_{1}, \Delta f_{2}$ and tie line power deviation $\Delta P_{\text {tie }}$ obtained by different control methods under $T_{g}$ decreasing $40 \%$ for case 3. (a) frequency deviation $\Delta f_{1} ;$ (b) frequency deviation $\Delta f_{2} ;(\mathbf{c})$ tie line power deviation $\Delta P_{\text {tie }}$. 


\subsection{Case 4: Robustness Test for Perturbed Parameter $T_{t}$}

Table 7 presents the performance comparison under two conditions including $T_{t}$ increasing $40 \%$ and decreasing $40 \%$ when $\Delta P_{L 1}=0.1$ and $\Delta P_{L 2}=0.1$. It is obvious that IAE, ITAE, ISE and ITSE obtained by MPC are all better than FA-PI, GA-PI and PEO-PI under all the conditions. The dynamic responses of the frequency deviations $\Delta f_{1}, \Delta f_{2}$, and tie line power deviation $\Delta P_{\text {tie }}$ obtained by MPC, PEO-PI, GA-PI and FA-PI under $T_{t}$ increasing $40 \%$ and decreasing $40 \%$ are shown in Figures 8 and 9 , respectively. Cleary, MPC is still prior to PEO-PI, GA-PI and FA-PI in terms of both transient and steady-state performance under the variations of parameter $T_{t}$.

Table 7. Performance comparison of MPC, PEO-PI, GA-PI and FA-PI for case 4.

\begin{tabular}{cccccc}
\hline Algorithm & Condition & IAE & ITAE & ISE & ITSE \\
\hline FA-PI [32] & & 44.68 & 115.67 & 6.35 & 9.69 \\
GA-PI [32] & $T_{t}$ & 64.83 & 241.76 & 9.14 & 20.39 \\
PEO-PI [43] & increases & 22.71 & 66.65 & 1.98 & 1.64 \\
MPC & $40 \%$ & 14.83 & 12.63 & 1.00 & 0.68 \\
\hline FA-PI [32] & & 42.36 & 112.38 & 5.57 & 8.39 \\
GA-PI [32] & $T_{t}$ & 59.21 & 209.39 & 8.00 & 17.02 \\
PEO-PI [43] & decreases & 19.32 & 61.32 & 1.47 & 1.06 \\
MPC & $40 \%$ & 9.04 & 5.25 & 0.48 & 0.18 \\
\hline
\end{tabular}

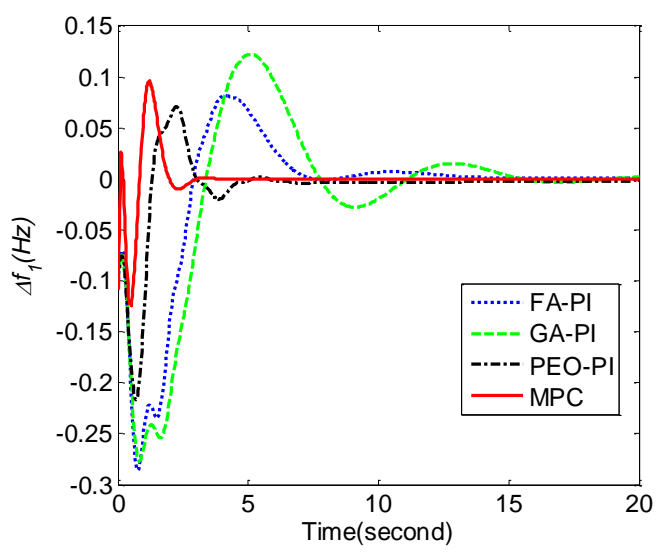

(a)

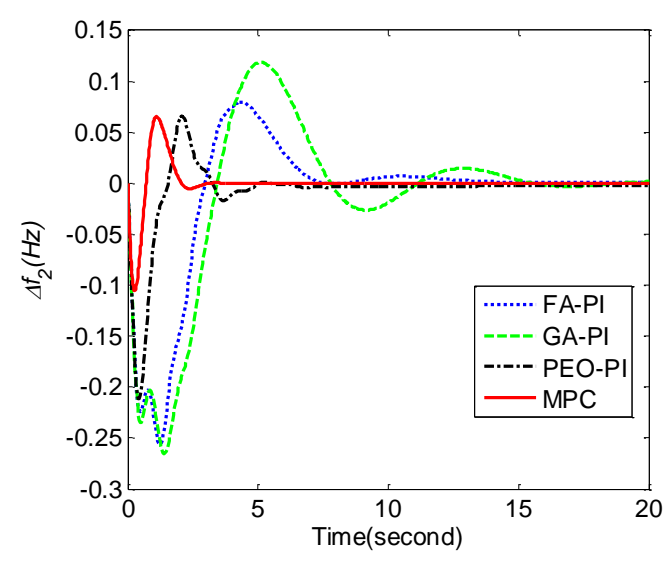

(b)

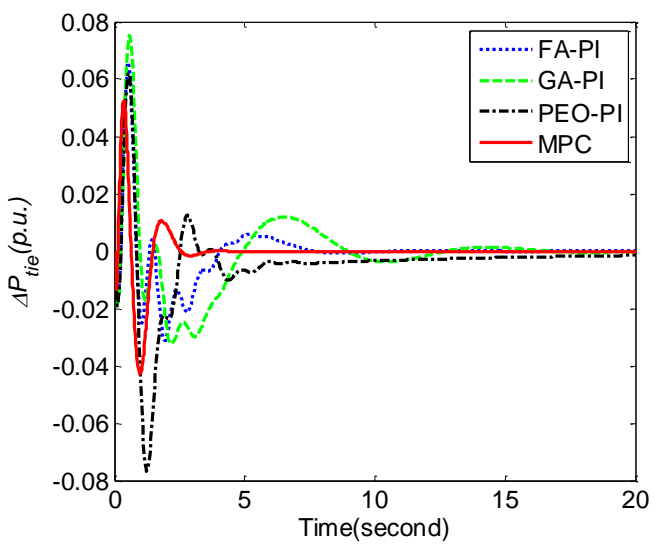

(c)

Figure 8. Comparison of frequency deviations $\Delta f_{1}, \Delta f_{2}$ and tie line power deviation $\Delta P_{\text {tie }}$ obtained by different control methods under $T_{t}$ increasing $40 \%$ for case 4 . (a) frequency deviation $\Delta f_{1} ;$ (b) frequency deviation $\Delta f_{2} ;(\mathbf{c})$ tie line power deviation $\Delta P_{\text {tie }}$. 


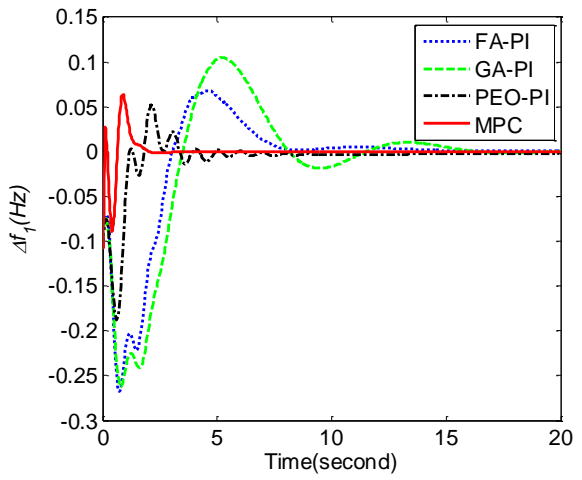

(a)

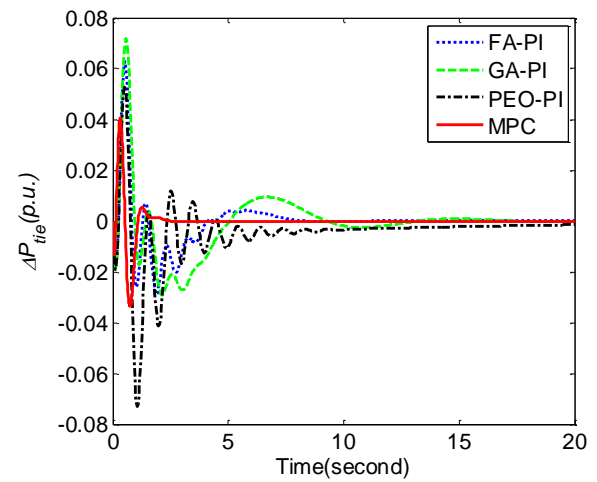

(b)

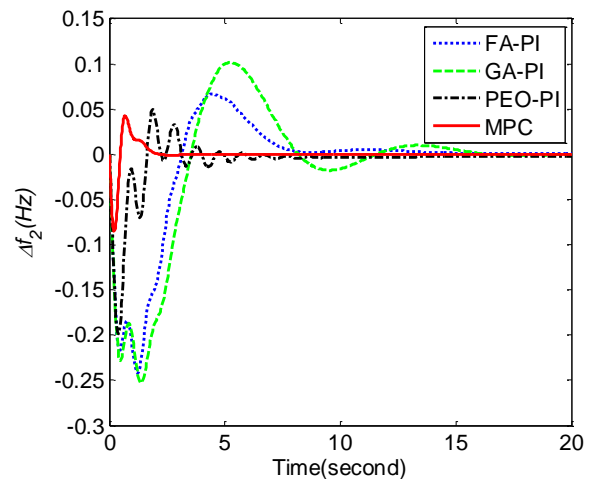

(c)

Figure 9. Comparison of frequency deviations $\Delta f_{1}, \Delta f_{2}$ and tie line power deviation $\Delta P_{\text {tie }}$ obtained by different control methods under $T_{t}$ decreasing $40 \%$ for case 4 . (a) frequency deviation $\Delta f_{1}$; (b) frequency deviation $\Delta f_{2} ;(\mathbf{c})$ tie line power deviation $\Delta P_{\text {tie }}$.

\subsection{Robustness Test for Dynamical Load Fluctuations}

In this subsection, two experiments have been done to further demonstrate the robustness of the proposed MPC method for the dynamical loads fluctuations of $\Delta P_{L 1}$ and $\Delta P_{L 2}$. More specifically, Figures 10 and 11 show the dynamic responses of frequency deviations $\Delta f_{1}, \Delta f_{2}$, and power deviations $\Delta P_{\text {tie, }}, \Delta P_{\mathrm{pv}}, \Delta P_{5}$ obtained by different control methods under dynamical fluctuations of $\Delta P_{L 1}$ and $\Delta P_{L 2}$, respectively. It is obvious that the proposed MPC performs better than PEO-PI, GA-PI and FA-PI due to its fast transient responses and less deviations of $\Delta f_{1}, \Delta f_{2}, \Delta P_{\text {tie, }}, \Delta P_{\mathrm{pv}}$, and $\Delta P_{5}$ under two conditions. Moreover, Table 8 further compares the performance indices such as IAE, ITAE, ISE and ITSE obtained by different control methods under two cases of dynamical load fluctuations. Clearly, MPC is superior to FA-PI, GA-PI and PEO-PI in terms of all indices. In other words, the proposed MPC method in this paper also outperforms these state-of-the-art PI control methods [32,43] for the LFC issue of a multi-area interconnected power system with PV generations even under the dynamical loads fluctuations. 


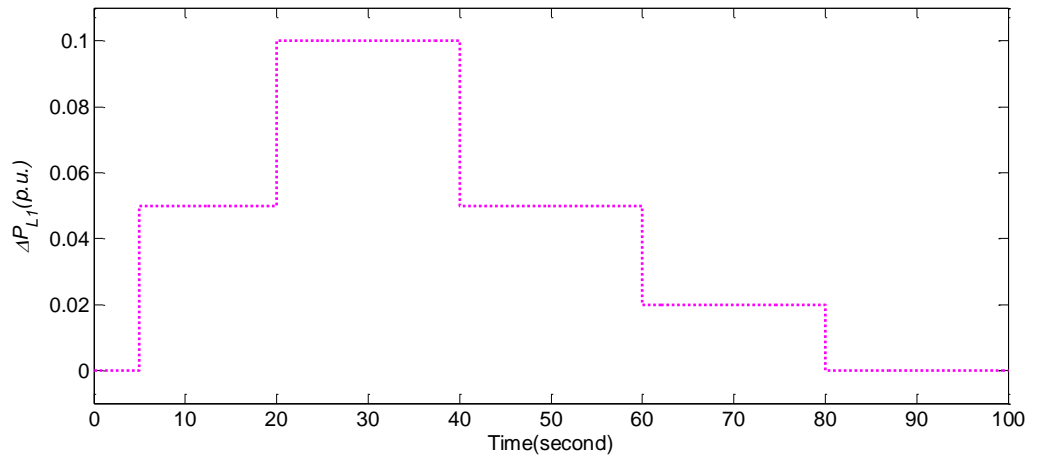

(a)

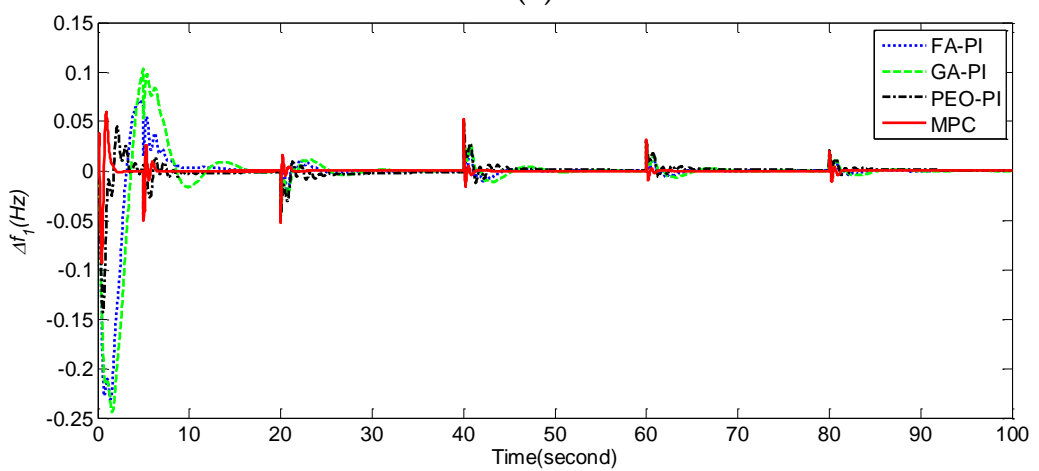

(b)

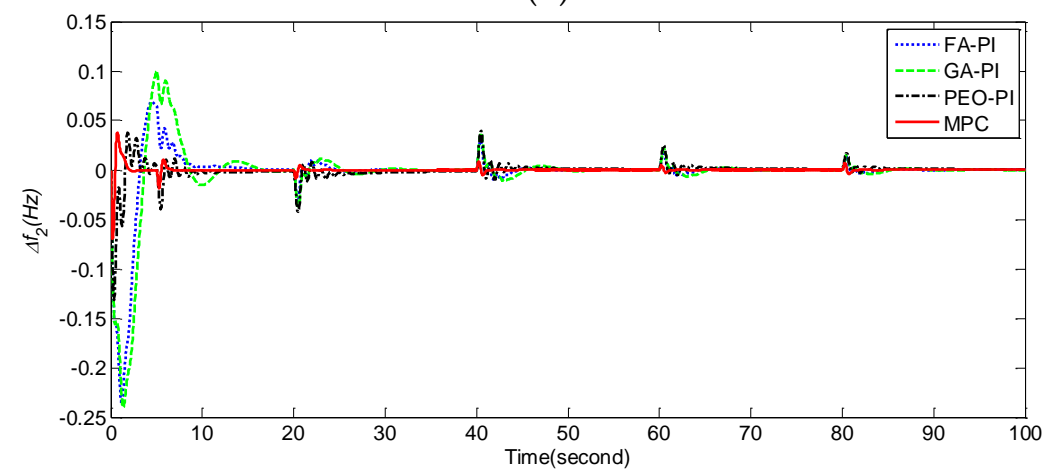

(c)

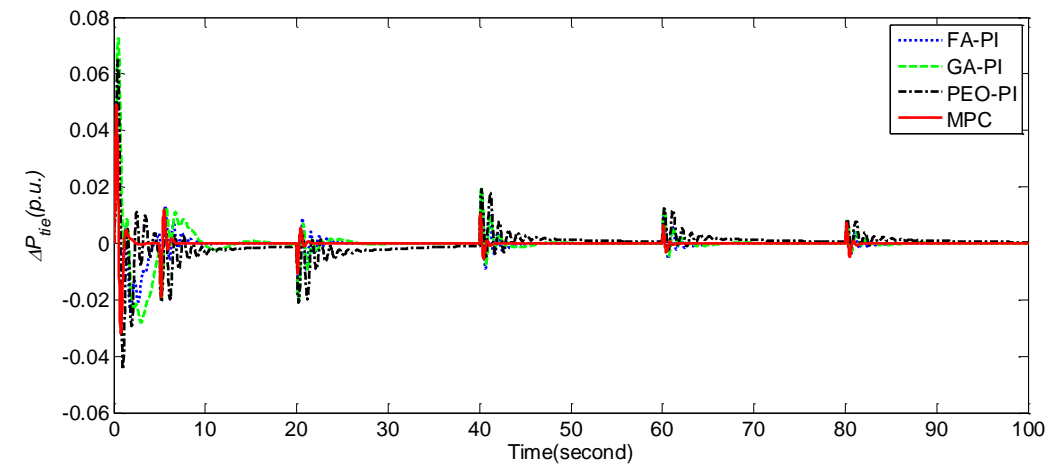

(d)

Figure 10. Cont. 


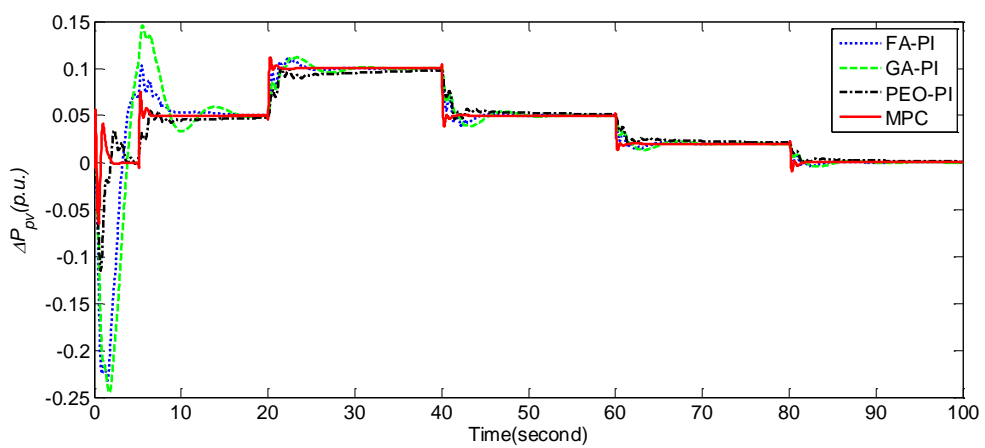

(e)

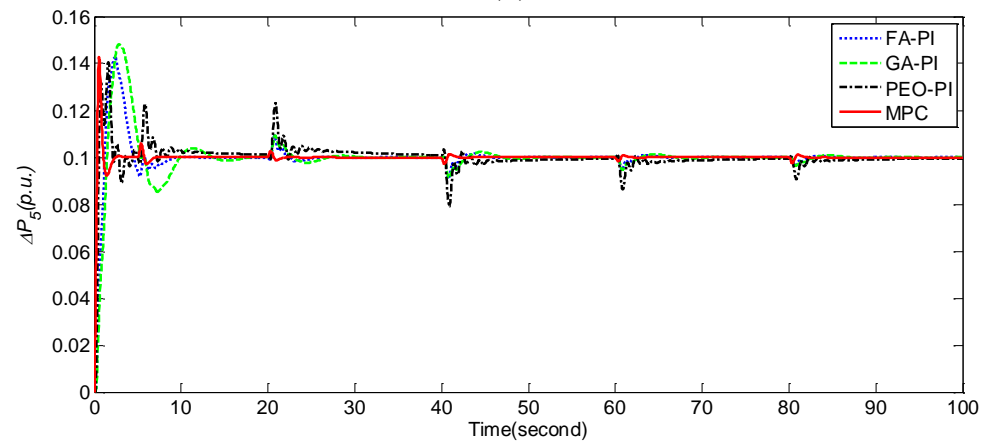

(f)

Figure 10. Comparison of frequency deviations $\Delta f_{1}, \Delta f_{2}$, and power deviations $\Delta P_{\text {tie }}, \Delta P_{\mathrm{pv}}, \Delta P_{5}$ obtained by different control methods under dynamical fluctuations of $\Delta P_{L 1}$ for case 5. (a) $\Delta P_{L 1}$; (b) $\Delta f_{1} ;$ (c) $\Delta f_{2} ;$ (d) $\Delta P_{\text {tie }} ;$ (e) $\Delta P_{\mathrm{pv}} ;$ (f) $\Delta P_{5}$.

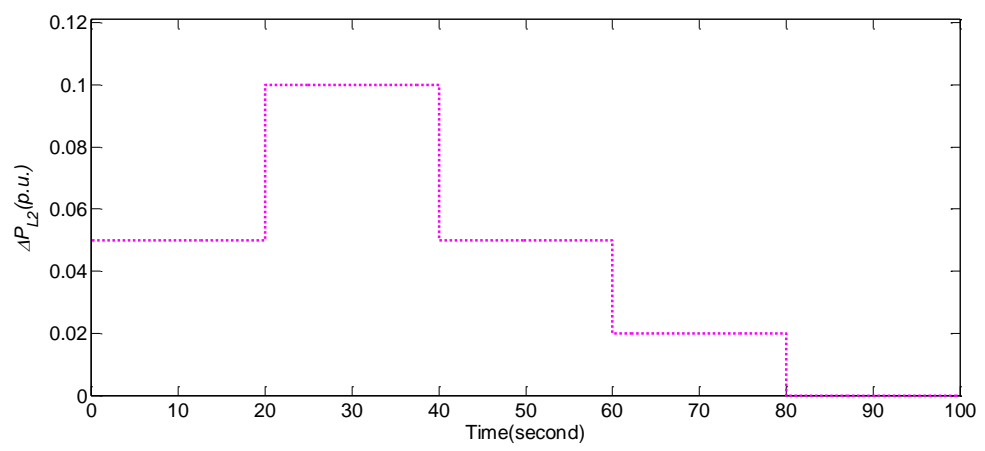

(a)

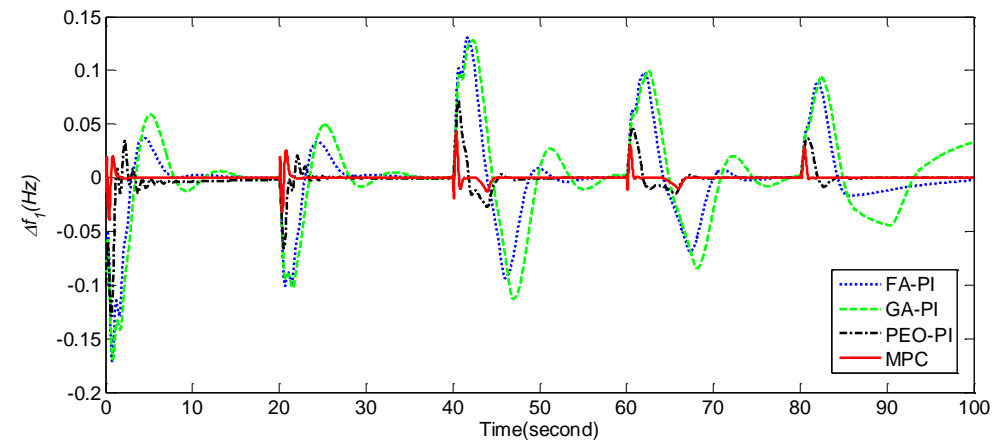

(b)

Figure 11. Cont. 


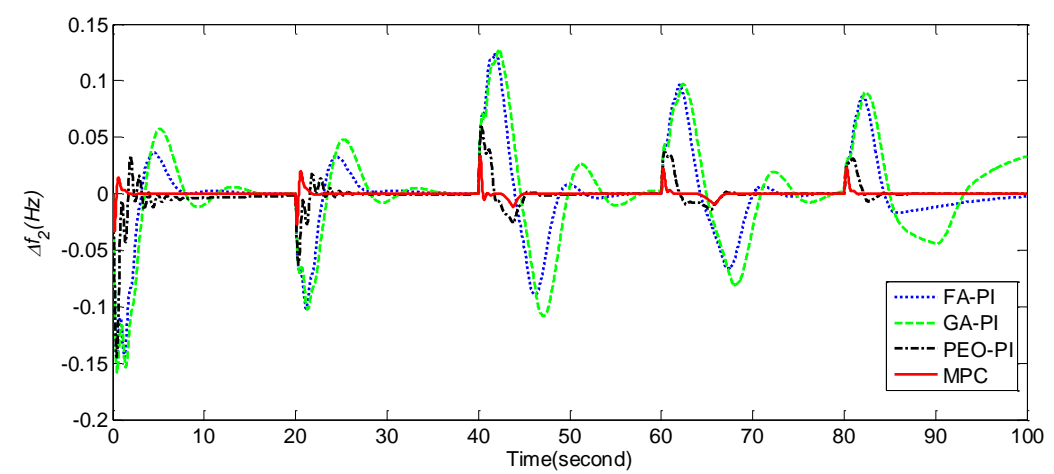

(c)

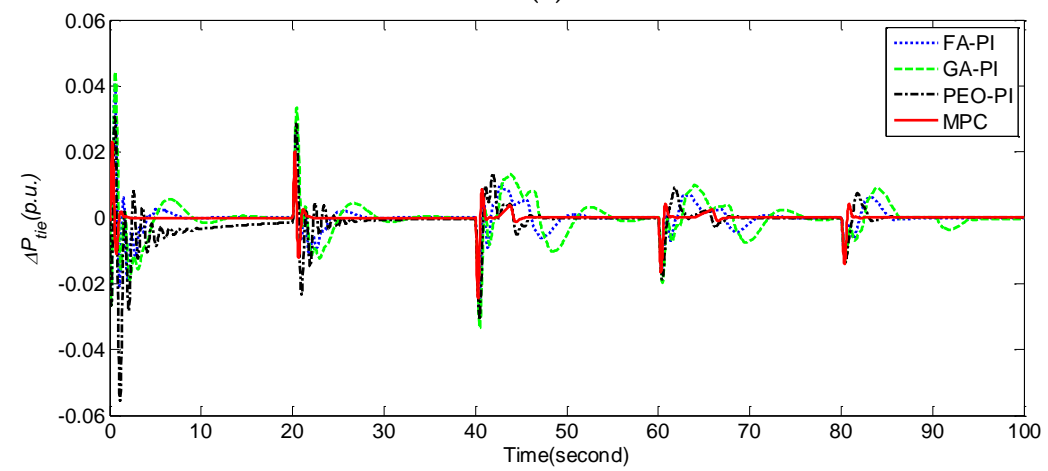

(d)

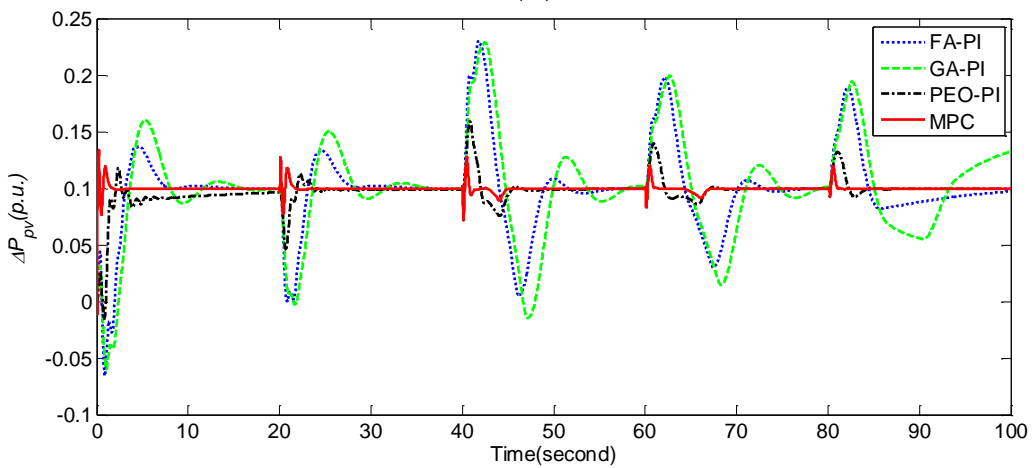

(e)

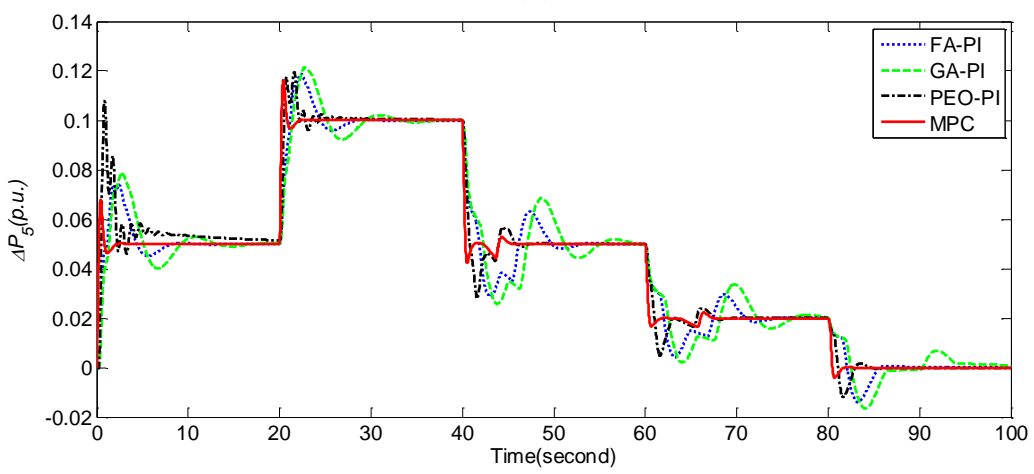

(f)

Figure 11. Comparison of frequency deviations $\Delta f_{1}, \Delta f_{2}$, and power deviations $\Delta P_{\text {tie }}, \Delta P_{\mathrm{pv}}, \Delta P_{5}$ obtained by different control methods under dynamical fluctuations of $\Delta P_{L 2}$ for case 6. (a) $\Delta P_{L 2}$; (b) $\Delta f_{1} ;$ (c) $\Delta f_{2} ;$ (d) $\Delta P_{\text {tie }} ;(\mathbf{e}) \Delta P_{\mathrm{pv}} ;$ (f) $\Delta P_{5}$. 
Table 8. Performance comparison of MPC, PEO-PI, GA-PI and FA-PI for dynamical load fluctuations.

\begin{tabular}{cccccc}
\hline Algorithm & Condition & IAE & ITAE & ISE & ITSE \\
\hline FA-PI [32] & Case & 50.18 & 502.38 & 5.35 & 12.58 \\
GA-PI [32] & 5:Dynamical & 71.70 & 829.83 & 7.57 & 22.8 \\
PEO-PI [43] & fluctuationsof & 32.60 & 908.93 & 0.85 & 7.12 \\
MPC & $\Delta P_{L 1}$ & $\mathbf{1 2 . 7 8}$ & $\mathbf{1 6 1 . 4 4}$ & $\mathbf{0 . 4 2}$ & $\mathbf{2 . 0 3}$ \\
\hline FA-PI [32] & Case 6: & 133.27 & 6034.24 & 8.62 & 341.94 \\
GA-PI [32] & Dynamical & 196.33 & 9514.9 & 12.8 & 541.8 \\
PEO-PI [43] & fluctuationsof & 39.06 & 1287.35 & 1.3 & $\mathbf{2 8 . 9 3}$ \\
MPC & $\Delta P_{L 2}$ & $\mathbf{1 4 . 0 2}$ & $\mathbf{4 6 8 . 5 6}$ & $\mathbf{0 . 3 2}$ & $\mathbf{6 . 9 2}$ \\
\hline
\end{tabular}

\section{Conclusions}

In this paper, an adaptive model predictive control (MPC) method is proposed for load frequency control (LFC) issue of a multi-area interconnected power system with PV generation. The key operations of this proposed method include formulating the LFC issue as a discrete-time state space model, obtaining the dynamic predictive model by introducing an expanded state vector, and rolling optimization of control output signal by gradient descent method based on a cost function minimizing the weighted sum of square predicted errors and square future control values. The simulation results on a typical two-area power system consisting of photovoltaic and thermal generator have shown that the proposed MPC method is superior to evolutionary algorithms-based PI control methods such as FA-PI [32], GA-PI [32], and PEO-PI [42,43] in terms of dynamic and steady-state performance in cases of normal condition, load disturbance and parameters uncertainty. To the best of the authors' knowledge, this work can be considered as the first contribution of MPC to the optimal LFC issue of a multi-area interconnected power system with PV generation. However, from the theoretical perspective, the optimal design issue of the weighting vectors, prediction horizon and control horizon in the proposed MPC method is still challenging. From the perspective of engineering practice, the proposed method will be further studied in depth by tuning the weighting vectors, prediction horizon and control horizon based on evolutionary algorithms, such as multi-objective optimization algorithms [46-48]. On the other hand, the extension of MPC to more complex power systems by taking into account the robust control performance indices [45] and real-time predictive power of renewable energy systems [49] is another significant subject of future investigation.

Acknowledgments: This work was partially supported by the National Natural Science Foundation of China (Nos. 51207112 and 61373158), the Zhejiang Provincial Natural Science Foundation of China (Nos. LY16F030011 and LZ16E050002), and the Zhejiang Province Science and Technology Planning Project (Nos.2014C31074, 2014C31093, and 2015C31157).

Author Contributions: Guo-Qiang Zeng proposed the novel idea behind this work, designed the algorithm framework, and prepared manuscript; Xiao-Qing Xie performed the simulations for the multi-area power system with PV generation; Min-Rong Chen analyzed the simulation results and improve the language. All authors approved the final manuscript.

Conflicts of Interest: The authors declare no conflict of interest.

\section{Nomenclature}

$\Delta f_{i} \quad$ Frequency deviation of area $i$

$\Delta P_{1} \quad$ The intermediate power deviation of PV

$\Delta P_{3} \quad$ Power deviation of governor

$\Delta P_{4} \quad$ Power deviation of steam turbine

$\Delta P_{5} \quad$ Power deviation of and re-heater

$\Delta P_{c i} \quad$ Control signal of area $i$

$\Delta P_{L \mathrm{i}} \quad$ Load changes 


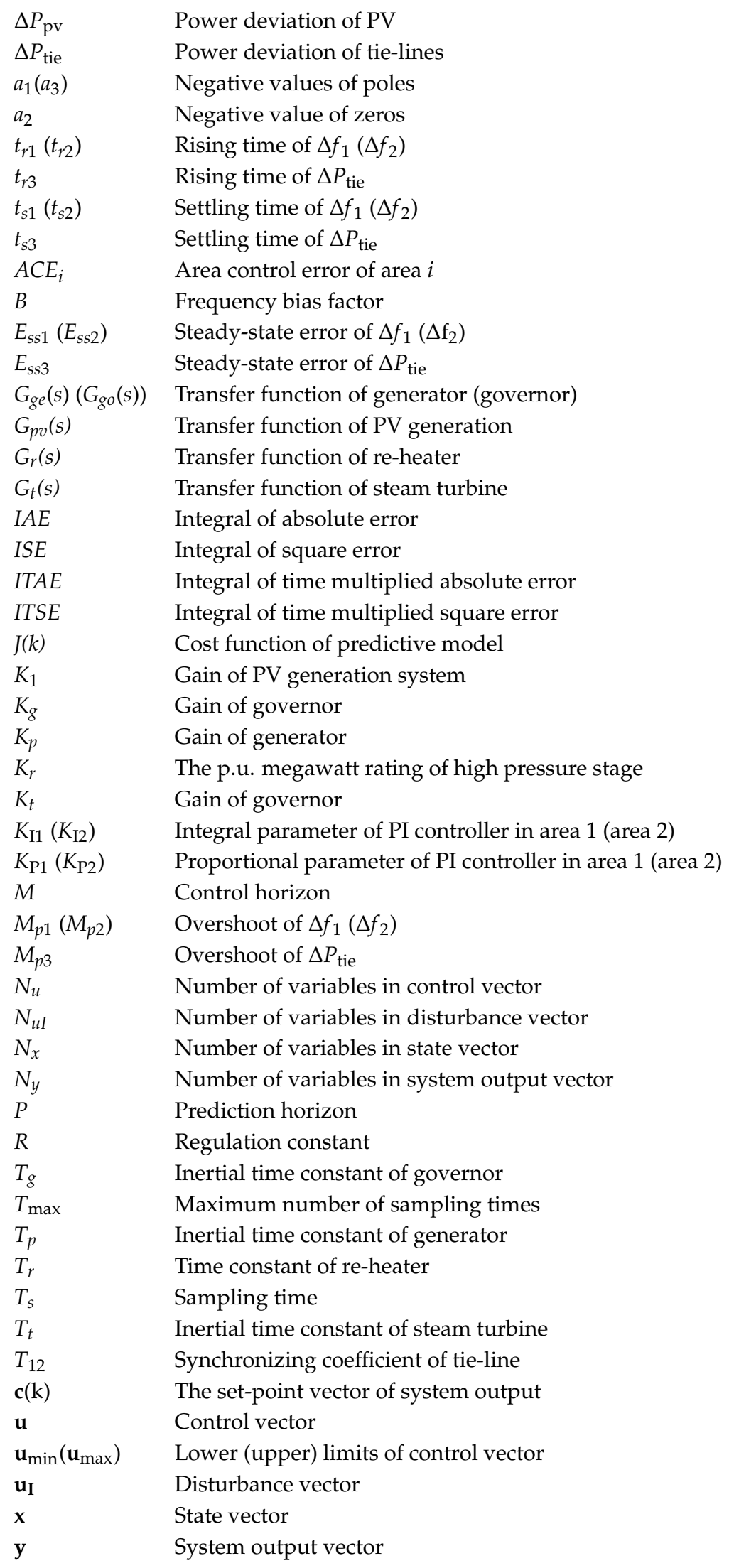




\begin{tabular}{|c|c|}
\hline $\mathbf{y}_{\min }\left(\mathbf{y}_{\max }\right)$ & Lower (upper) limits of $\mathbf{y}$ \\
\hline $\mathbf{y}(k+p \mid k)$ & The $(k+p)$-th predictive output at $k$-th time \\
\hline $\mathbf{y}_{\mathbf{r}}(k+p \mid k)$ & The $(k+p)$-th predictive reference \\
\hline$\Delta \mathbf{u}$ & Incremental form of control vector \\
\hline$\Delta \mathbf{u}_{\mathrm{I}}$ & Incremental form of disturbance vector \\
\hline$\Delta \mathbf{u}_{\min }\left(\Delta \mathbf{u}_{\max }\right)$ & Lower (upper) limits of $\Delta \mathbf{u}$ \\
\hline$\Delta \mathbf{x}$ & Incremental state vector \\
\hline$\Delta \mathbf{y}$ & Incremental form of system output vector \\
\hline$\Delta \mathbf{U}$ & Predictive control vector \\
\hline$\Delta \mathbf{U}_{\mathrm{I}}$ & Predictive disturbance vector \\
\hline A & Continuous-time system matrix \\
\hline $\mathbf{A}_{\mathrm{d}}$ & Discrete-time system matrix \\
\hline B & Continuous-time control matrix \\
\hline $\mathbf{B}_{\mathbf{d}}$ & Continuous-time control matrix \\
\hline $\mathbf{B}_{\mathbf{I}}$ & Continuous-time disturbance matrix \\
\hline $\mathbf{B}_{\text {Id }}$ & Discrete-time disturbance matrix \\
\hline $\mathrm{C}$ & System output matrix \\
\hline $\mathrm{C}_{\mathrm{z}}$ & Extended system output matrix \\
\hline E & Identity matrix \\
\hline G & Extended discrete-time system matrix \\
\hline $\mathbf{H}$ & Extended discrete-time control matrix \\
\hline $\mathbf{H}_{\mathrm{I}}$ & Extended discrete-time disturbance matrix \\
\hline Q & Weighting vector of square predicted errors \\
\hline $\mathbf{R}$ & Weighting vector of square future control \\
\hline $\mathbf{Y}_{\mathrm{P}}(k)$ & Predictive output vector \\
\hline $\mathbf{Y}_{\mathrm{r}}(k)$ & Reference predictive vector \\
\hline $\mathrm{Z}(k)$ & Extend state vector \\
\hline$\lambda$ & Soften factor \\
\hline$\phi$ & Predictive system matrix \\
\hline$\psi$ & Predictive control matrix \\
\hline$\psi_{I}$ & Predictive disturbance matrix \\
\hline
\end{tabular}

\section{References}

1. Pandey, S.K.; Mohanty, S.R.; Kishor, N. A literature survey on load-frequency control for conventional and distribution generation power systems. Renew. Sustain. Energy Rev. 2013, 25, 318-334. [CrossRef]

2. Wu, Y.; Wei, Z.; Weng, J.; Li, X.; Deng, R.H. Resonance attacks on load frequency control of smart grids. IEEE Trans. Smart Grid 2017. [CrossRef]

3. Tan, W. Unified tuning of PID load frequency controller for power systems via IMC. IEEE Trans. Power Syst. 2010, 25, 341-350. [CrossRef]

4. Saxena, S.; Hote, Y.V. Decentralized PID load frequency control for perturbed multi-area power systems. Int. J. Electr. Power Energy Syst. 2016, 81, 405-415. [CrossRef]

5. Golpira, H.; Bevrani, H. Application of GA optimization for automatic generation control design in an interconnected power system. Energy Convers. Manag. 2011, 52, 2247-2255. [CrossRef]

6. Daneshfar, F.; Bevrani, H. Multiobjective design of load frequency control using genetic algorithms. Int. J. Electr. Power Energy Syst. 2012, 42, 257-263. [CrossRef]

7. Naidu, K.; Mokhlis, H.; Bakar, A.H.A. Multiobjective optimization using weighted sum artificial bee colony algorithm for load frequency control. Int. J. Electr. Power Energy Syst. 2014, 55, 657-667. [CrossRef]

8. Panda, S.; Yegireddy, N.K. Automatic generation control of multi-area power system using multi-objective non-dominated sorting genetic algorithm-II. Int. J. Electr. Power Energy Syst. 2013, 53, 54-63. [CrossRef]

9. Chuang, N. Robust $\mathrm{H} \infty$ load-frequency control in interconnected power systems. IET Control Theory Appl. 2016, 10, 67-75. [CrossRef]

10. Ersdal, A.M.; Lars, I.; Kjetil, U. Model predictive load-frequency control. IEEE Trans. Power Syst. 2016, 31, 777-785. [CrossRef] 
11. Ojaghi, P.; Rahmani, M. LMI-based robust predictive load frequency control for power systems with communication delays. IEEE Trans. Power Syst. 2017, 32, 4091-4100. [CrossRef]

12. Liu, X.; Kong, X.; Lee, K.Y. Distributed model predictive control for load frequency control with dynamic fuzzy valve position modeling for hydro-thermal power system. IET Control Theory Appl. 2016, 10, 1653-1664. [CrossRef]

13. Ersdal, A.M.; Imsland, L.; Uhlen, K.; Fabozzi, D.; Thornhill, N.F. Model predictive load-frequency control taking into account imbalance uncertainty. Control Eng. Pract. 2016, 53, 139-150. [CrossRef]

14. Ma, M.; Zhang, C.; Liu, X.; Chen, H. Distributed model predictive load frequency control of multi-area power system after deregulation. IEEE Trans. Ind. Electron. 2017, 64, 5129-5139. [CrossRef]

15. Mi, Y.; Fu, Y.; Wang, C.; Wang, P. Decentralized sliding mode load frequency control for multi-area power systems. IEEE Trans. Power Syst. 2013, 28, 4301-4309. [CrossRef]

16. Prasad, S.; Purwar, S.; Kishor, N. Non-linear sliding mode load frequency control in multi-area power system. Control Eng. Pract. 2017, 61, 81-92. [CrossRef]

17. Sabahiand, K.; Teshnehlab, M. Recurrent fuzzy neural network by using feedback error learning approaches for LFC in interconnected power system. Energy Convers. Manag. 2009, 50, 938-946.

18. Saxena, S.; Hote, Y.V. Stabilization of perturbed system via IMC: An application to load frequency control. Control Eng. Pract. 2017, 64, 61-73. [CrossRef]

19. Chen, H.Y.; Ye, R.; Wang, X.D.; Lu, R.G. Cooperative control of power system load and frequency by using differential games. IEEE Trans. Control Syst. Technol. 2015, 23, 882-897. [CrossRef]

20. Panda, S.; Mohanty, B.; Hota, P.K. Hybrid BFOA-PSO algorithm for automatic generation control of linear and nonlinear interconnected power systems. Appl. Soft Comput. 2013, 13, 4718-4730. [CrossRef]

21. Sahu, R.K.; Panda, S.; Rout, U.K. DE optimized parallel 2-DOF PID controller for load frequency control of power system with governor dead-band nonlinearity. Int. J. Electr. Power Energy Syst. 2013, 49, 19-33. [CrossRef]

22. Mohanty, B.; Panda, S.; Hota, P.K. Controller parameters tuning of differential evolution algorithm and its application to load frequency control of multi-source power system. Int. J. Electr. Power Energy Syst. 2014, 54, 77-85. [CrossRef]

23. Rakhshani, E.; Luna, A.; Rouzbehi, K.; Rodriguez, P. Application of imperialist competitive algorithm to design an optimal controller for LFC problem. In Proceedings of the 38th Annual Conference on IEEE Industrial Electronics Society, Montreal, QC, Canada, 25-28 October 2012; pp. 1223-1227.

24. Padhan, S.; Sahu, R.K.; Panda, S. Application of firefly algorithm for load frequency control of multi-area interconnected power system. Electr. Power Compon. Syst. 2014, 42, 1419-1430. [CrossRef]

25. Fini, M.H.; Yousefi, G.R.; Alhelou, H.H. Comparative study on the performance of many-objective and single-objective optimization algorithms in tuning load frequency controllers of multi-area power systems. IET Gener. Transm. Distrib. 2016, 10, 2915-2923. [CrossRef]

26. Mohamed, T.H.; Morel, J.; Bevrani, H.; Hiyama, T. Model predictive based load frequency control design concerning wind turbines. Int. J. Electr. Power Energy Syst. 2012, 43, 859-867. [CrossRef]

27. Bevrani, H.; Daneshmand, P.R. Fuzzy logic-based load-frequency control concerning high penetration of wind turbines. IEEE Syst. J. 2012, 6, 173-180. [CrossRef]

28. Qian, D.; Tong, S.; Liu, H.; Liu, X. Load frequency control by neural-network-based integral sliding mode for nonlinear power systems with wind turbines. Neurocomputing 2016, 173, 875-885. [CrossRef]

29. Liu, X.; Zhang, Y.; Lee, K.Y. Coordinated distributed MPC for load frequency control of power system with wind farms. IEEE Trans. Ind. Electron. 2017, 64, 5140-5150. [CrossRef]

30. Ma, M.; Liu, X.; Zhang, C. LFC for multi-area interconnected power system concerning wind turbines based on DMPC. IET Gener. Transm. Distrib. 2017, 11, 2689-2696. [CrossRef]

31. Kumar, L.S.; Kumar, G.N.; Madichetty, S. Pattern search algorithm based automatic online parameter estimation for AGC with effects of wind power. Int. J. Electr. Power Energy Syst. 2017, 84, 135-142. [CrossRef]

32. Abd-Elazim, S.M.; Ali, E.S. Load frequency controller design of a two-area system composing of PV grid and thermal generator via firefly algorithm. Neural Comput. Appl. 2016. [CrossRef]

33. Camacho, E.F.; Alba, C.B. Model Predictive Control; Springer Science \& Business Media: Berlin, Germany, 2013.

34. Mayne, D.Q. Model predictive control: Recent developments and future promise. Automatica 2014, 50, 2967-2986. [CrossRef] 
35. Kouro, S.; Cortés, P.; Vargas, R.; Ammann, U.; Rodríguez, J. Model predictive control—A simple and powerful method to control power converters. IEEE Trans. Ind. Electron. 2009, 56, 1826-1838. [CrossRef]

36. Rodriguez, J.; Kazmierkowski, M.P.; Espinoza, J.R.; Zanchetta, P.; Abu-Rub, H.; Young, H.A.; Rojas, C.A. State of the art of finite control set model predictive control in power electronics. IEEE Trans. Ind. Inf. 2013, 9, 1003-1016. [CrossRef]

37. Vazquez, S.; Leon, J.I.; Franquelo, L.G.; Rodriguez, J.; Young, H.A.; Marquez, A.; Zanchetta, P. Model predictive control: A review of its applications in power electronics. IEEE Ind. Electron. Mag. 2014, 8, 16-31. [CrossRef]

38. Geyer, T.; Quevedo, D.E. Performance of multistep finite control set model predictive control for power electronics. IEEE Trans. Power Electron. 2015, 30, 1633-1644. [CrossRef]

39. Vazquez, S.; Rodriguez, J.; Rivera, M.; Franquelo, L.G.; Norambuena, M. Model predictive control for power converters and drives: Advances and trends. IEEE Trans. Ind. Electron. 2017, 64, 935-947. [CrossRef]

40. Nguyen, T.T.; Yoo, H.J.; Kim, H.M. Analyzing the impacts of system parameters on MPC-based frequency control for a stand-alone microgrid. Energies 2017, 10, 417. [CrossRef]

41. Kerdphol, T.; Rahman, F.; Mitani, Y.; Hongesombut, K.; Kufeoglu, S. Virtual inertia control-based model predictive control for microgrid frequency stabilization considering high renewable energy integration. Sustainability 2017, 9, 773. [CrossRef]

42. Lu, Y.Z.; Chen, Y.W.; Chen, M.R.; Chen, P.; Zeng, G.Q. Extremal Optimization: Fundamentals, Algorithms, and Applications; CRC Press \& Chemical Industry Press: Boca Raton, FL, USA, 2016.

43. Zeng, G.Q.; Chen, J.; Chen, M.R.; Dai, Y.X.; Li, L.M.; Lu, K.D.; Zheng, C.W. Design of multivariable PID controllers using real-coded population-based extremal optimization. Neurocomputing 2015, 151, 1343-1353. [CrossRef]

44. Mohamed, T.H.; Bevrani, H.; Hassan, A.A.; Hiyama, T. Decentralized model predictive based load frequency control in an interconnected power system. Energy Convers. Manag. 2011, 52, 1208-1214. [CrossRef]

45. Bevrani, H. Robust Power System Frequency Control, 2nd ed.; Springer: New York, NY, USA, 2014.

46. Zeng, G.Q.; Chen, J.; Dai, Y.X.; Li, L.M.; Zheng, C.W.; Chen, M.R. Design of fractional order PID controller for automatic regulator voltage system based on multi-objective extremal optimization. Neurocomputing 2015, 160, 173-184. [CrossRef]

47. Zeng, G.Q.; Chen, J.; Li, L.M.; Chen, M.R.; Wu, L.; Dai, Y.X.; Zheng, C.W. An improved multi-objective population-based extremal optimization algorithm with polynomial mutation. Inf. Sci. 2016, 330, 49-73. [CrossRef]

48. Wang, H.; Zeng, G.Q.; Dai, Y.X.; Bi, D.Q.; Sun, J.L.; Xie, X. Q. Design of fractional order frequency PID controller for an islanded microgrid: A multi-objective extremal optimization method. Energies 2017, 10, 1502. [CrossRef]

49. Quan, D.M.; Ogliari, E.; Grimaccia, F.; Leva, S.; Mussetta, M. Hybrid model for hourly forecast of photovoltaic and wind power. In Proceedings of the IEEE International Conference on Fuzzy Systems, Hyderabad, India, 7-10 July 2013; pp. 1-6.

(C) 2017 by the authors. Licensee MDPI, Basel, Switzerland. This article is an open access article distributed under the terms and conditions of the Creative Commons Attribution (CC BY) license (http:/ / creativecommons.org/licenses/by/4.0/). 